IV

الجوانب السلوكية للزراع المرتبطة بأساليب ترشيد إستخدام مياه الرى

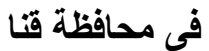

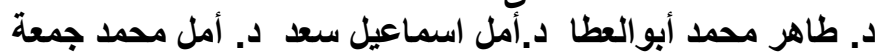

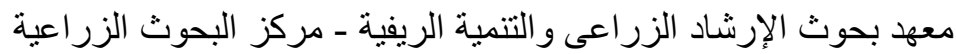

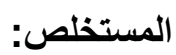

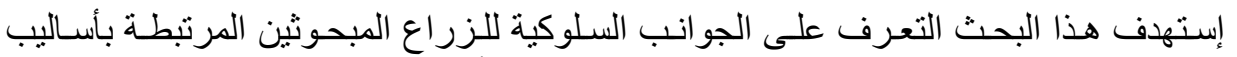

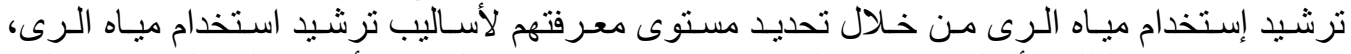

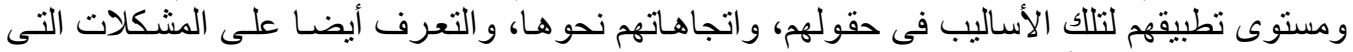

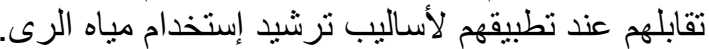

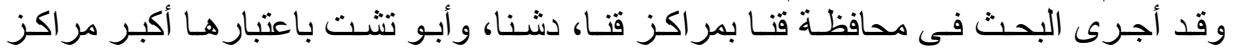

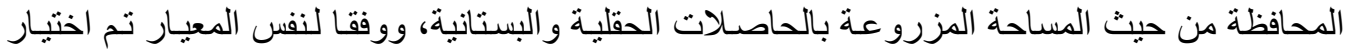

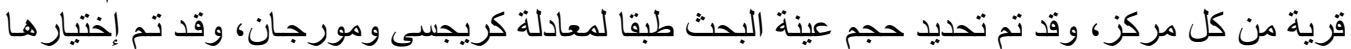

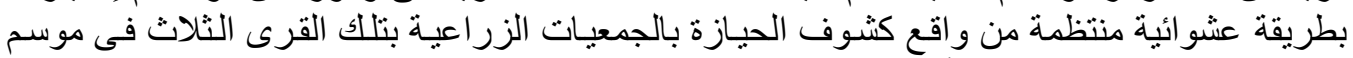

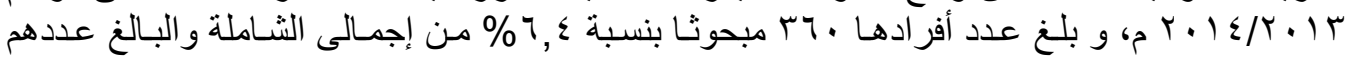

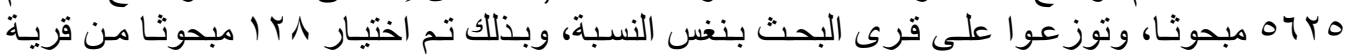

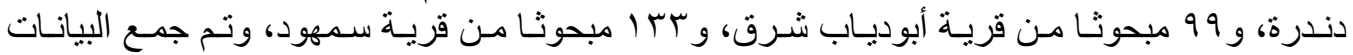

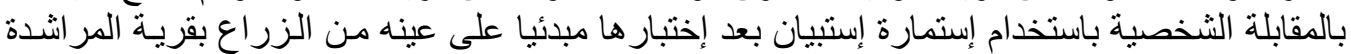

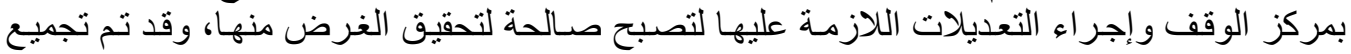

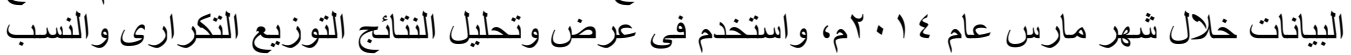

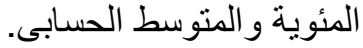

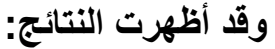

ـ مستوى معرفة الزراع المبحوثين لأساليب نرشيد إستخدام مياه الرى كان متوسطاً حيث بلغ المنوسط

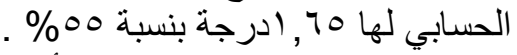
ـ مستوى تطبيق الزراع المبحوثين لأساليب ترشيد إستخدام مياه الرى كان متوسطاً حيث بلغ المتوسط

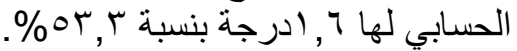

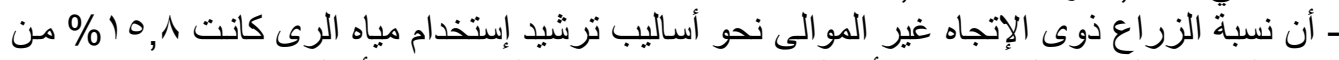

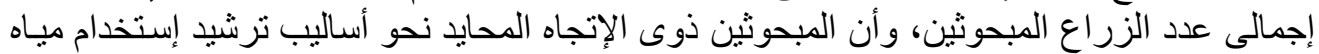

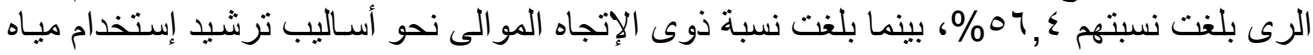

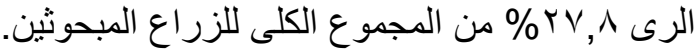

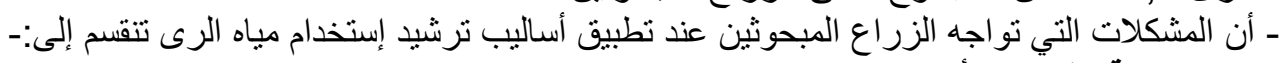

مشكلات خاصة بالزراع الناع وأهمها:

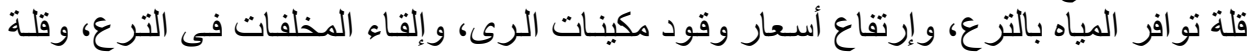

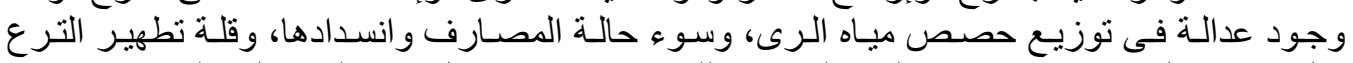

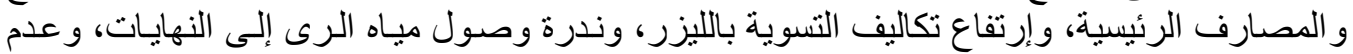

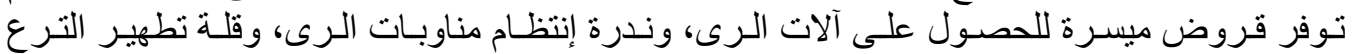

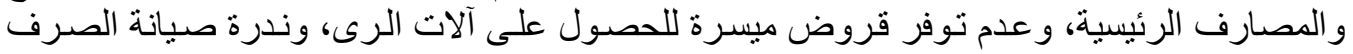

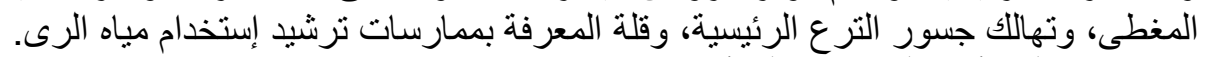
مشكلات خاصة بالأنشطة الإرشادية وأهرات الرمها:

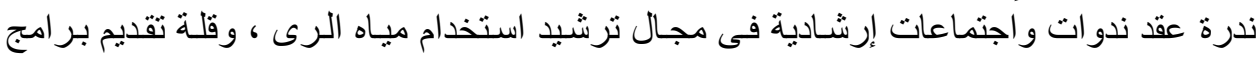

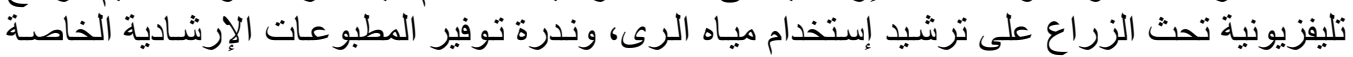

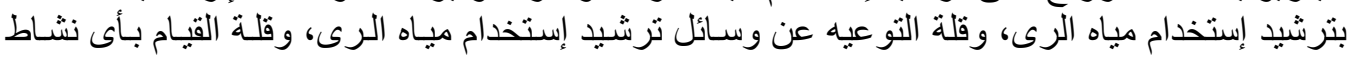

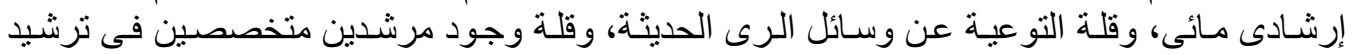

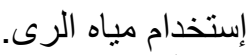

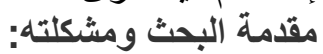

Fayoum J. Agric. Res. \& Dev., Vol. 27, No.2, July, 2014 
11

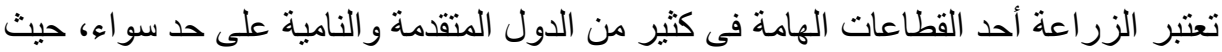

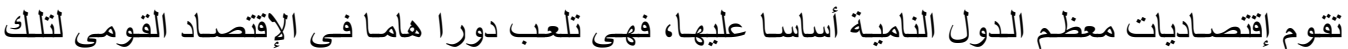

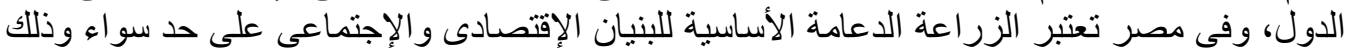

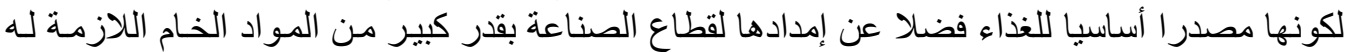

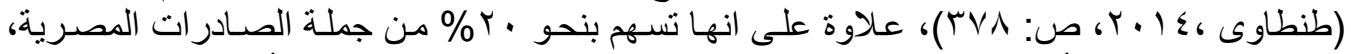
ومن ثم توفير النقد الأجنبى اللازم لتنفيذ خطط التنمية الإقتصادية و الإجتماعية كما أن نسبة العاملين بها التها

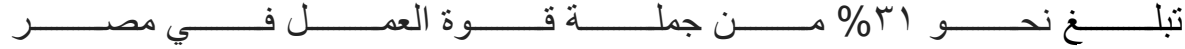

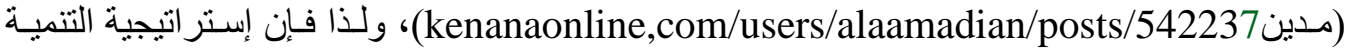

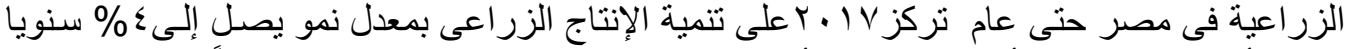

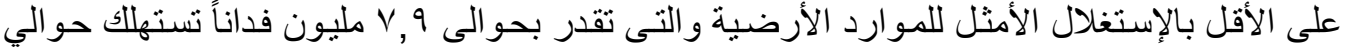

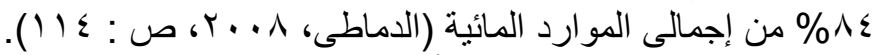

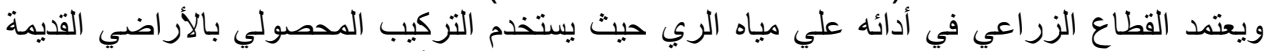

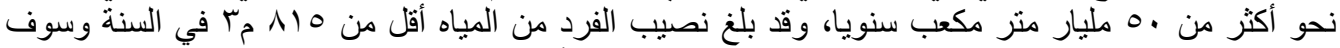

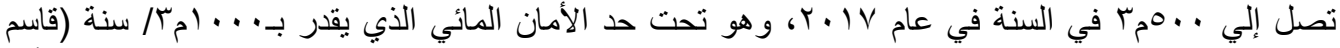

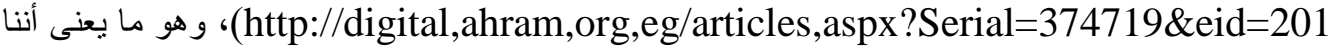

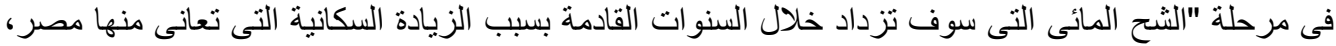

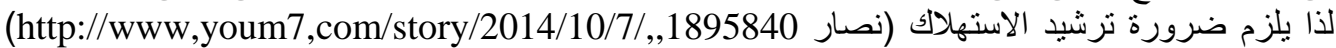

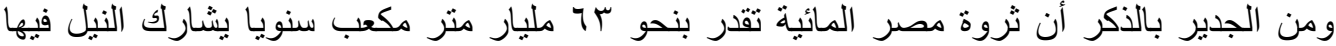

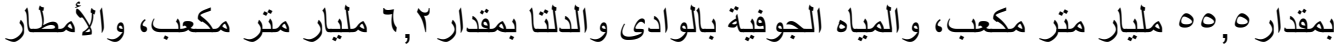

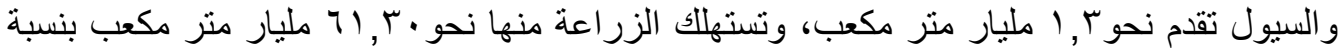

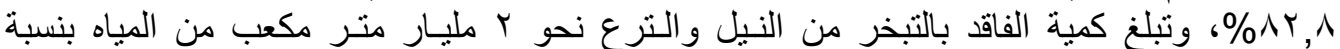

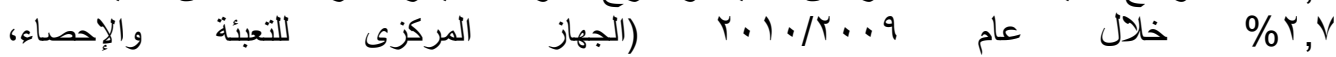

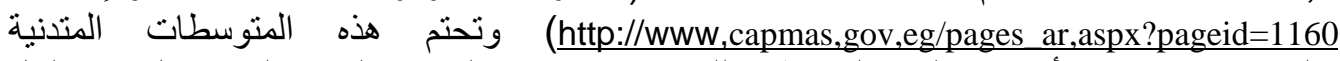
و المتناقصة سنة بعد أخري والنمو المضطرد للسكان ومحدودية الموارد المائية التي يشكل نهر النيل

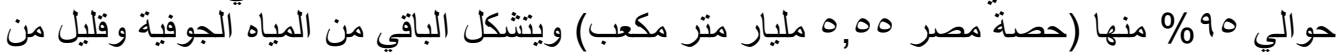

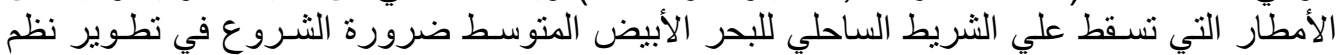

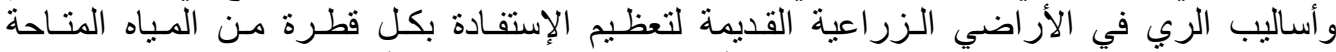
لتوفير مياه رثئ (بhttp://digital,ahram,org,eg/articles,aspx?Serial=374719\&eid=201

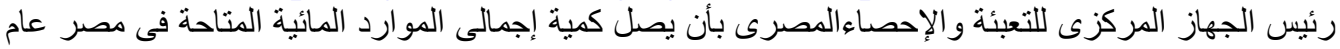

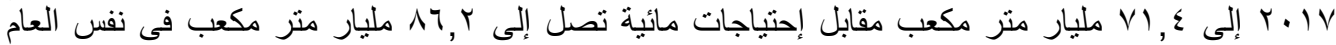

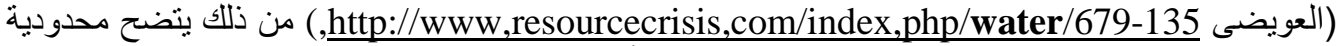

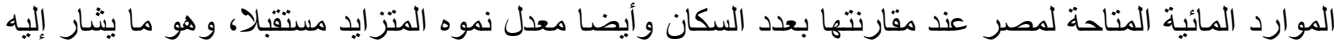

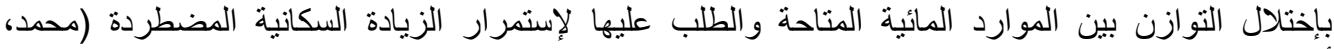

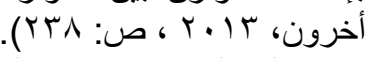

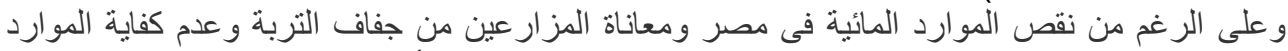

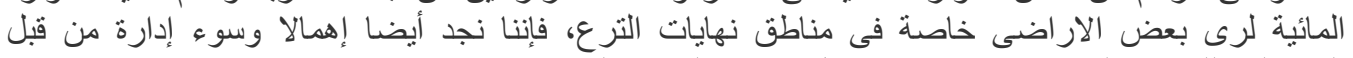

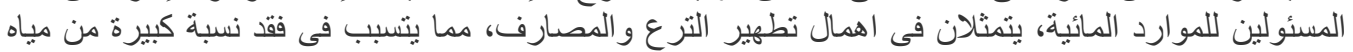

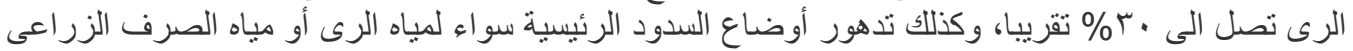

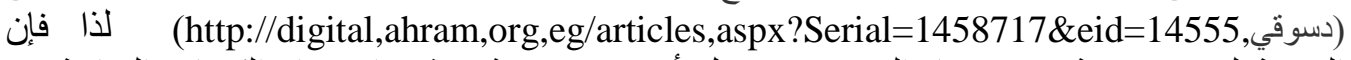
القضية لم تعد قضية توفير مياه الرى فحسب بل أصبحت قضية ترشيد إستخدام الكميات المتاحة من فئ

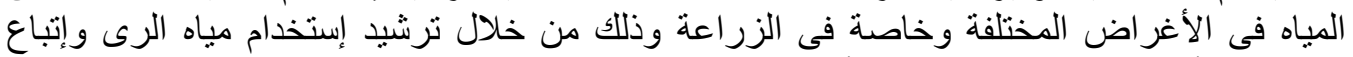

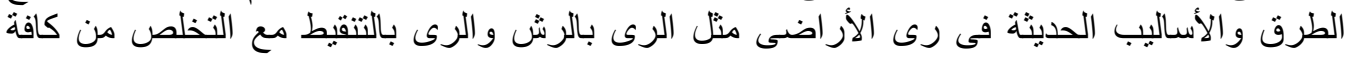

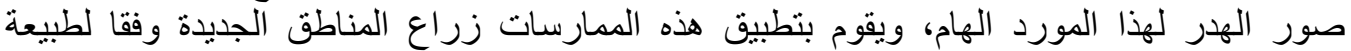

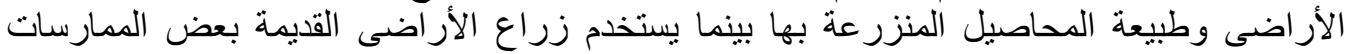

Fayoum J. Agric. Res. \& Dev., Vol. 27, No.2, July, 2014 
19

الإرو ائية التقليدية والتى تركز بصفة أساسية على إستخدام طريقة الرى بالغمر ويرجع ذللك إلى العديد

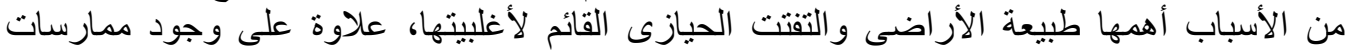

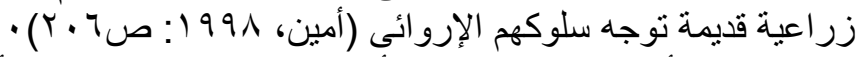

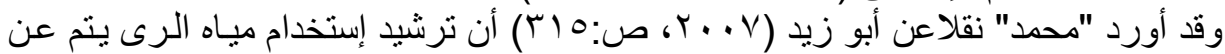

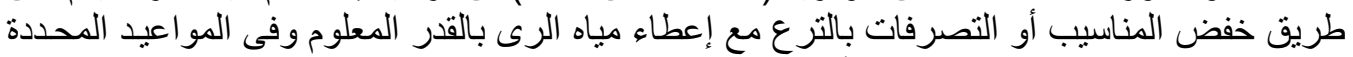

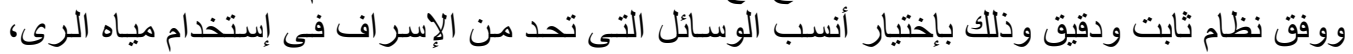

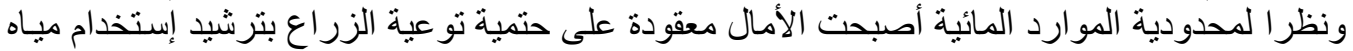

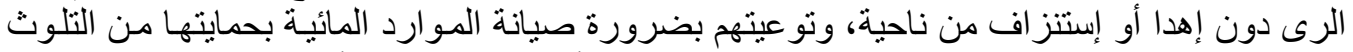

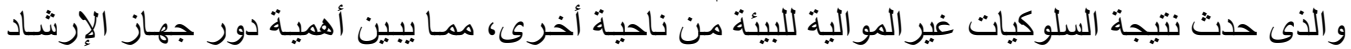

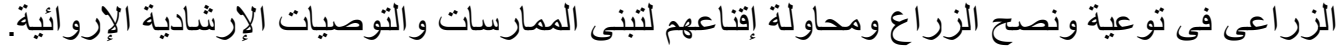

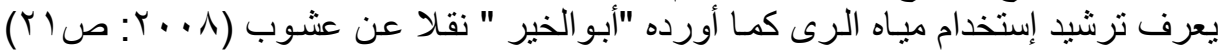

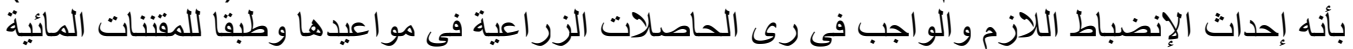

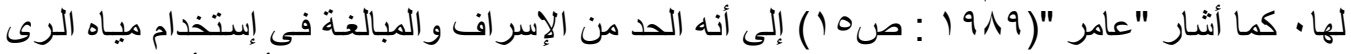

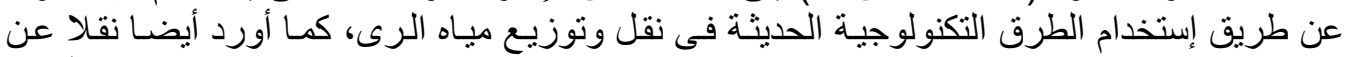

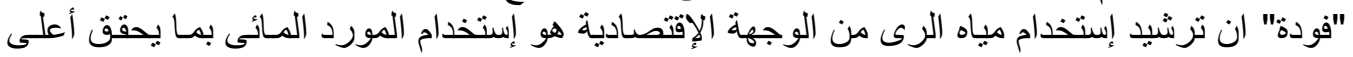

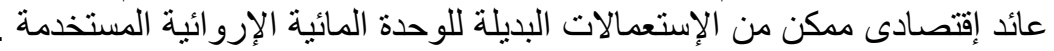

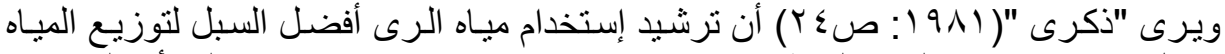

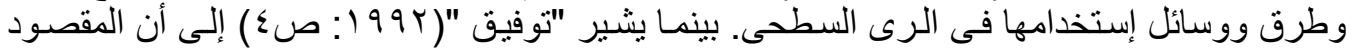

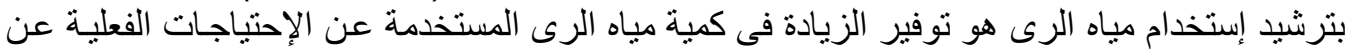

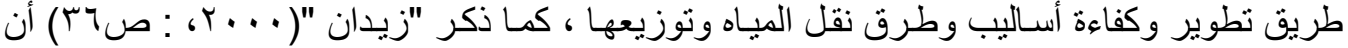

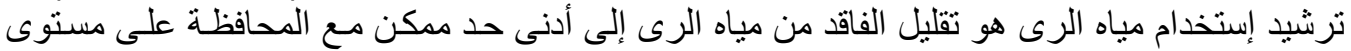

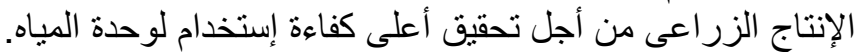

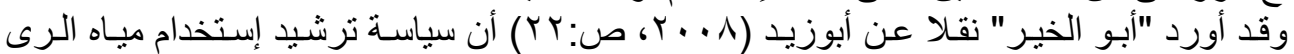

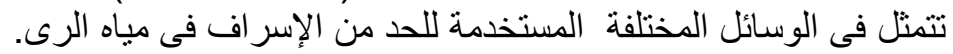

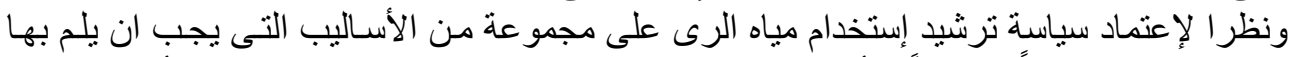

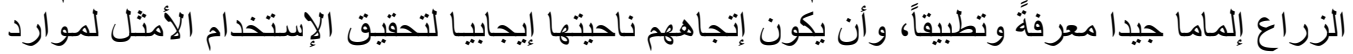

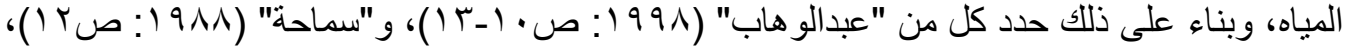

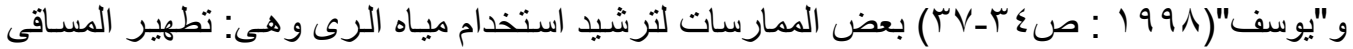

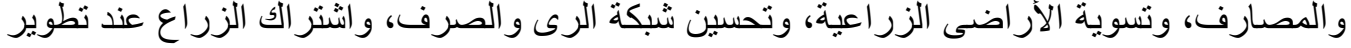

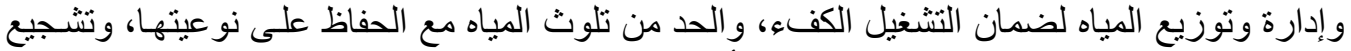

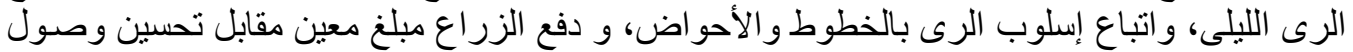

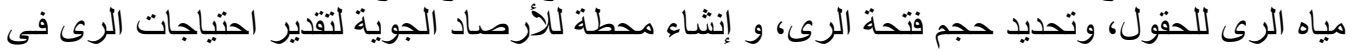

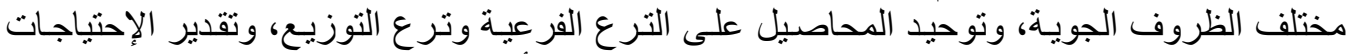

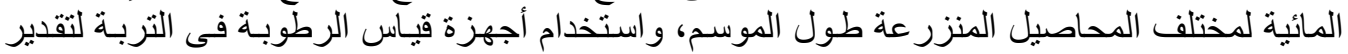

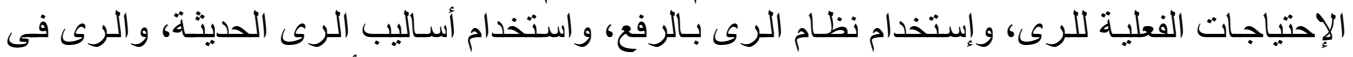

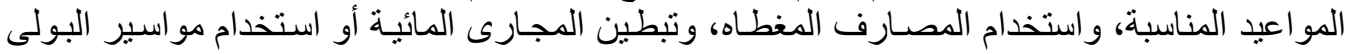

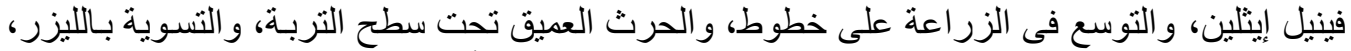

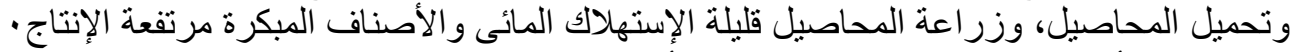

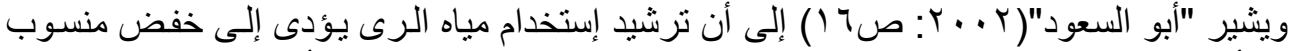

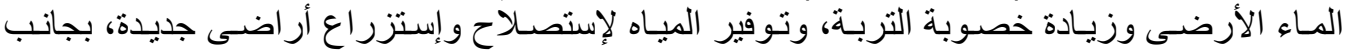
المحافظة على المو ارد الأرضية المتاحة.

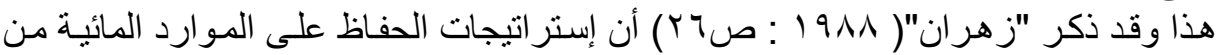

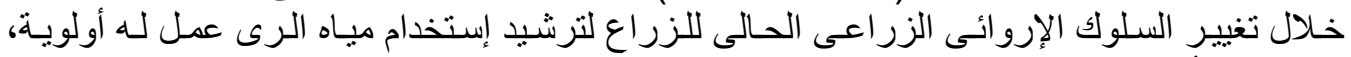

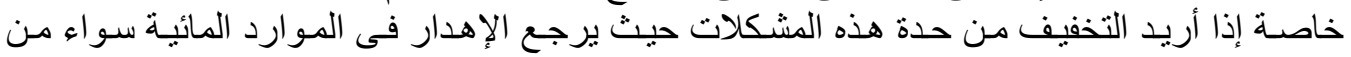

Fayoum J. Agric. Res. \& Dev., Vol. 27, No.2, July, 2014 
r.

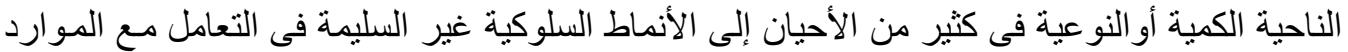

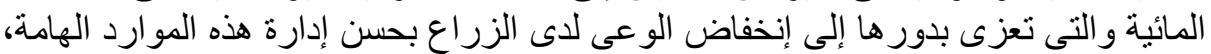

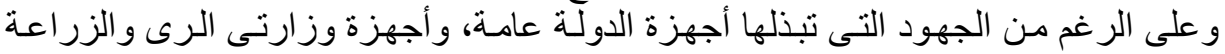

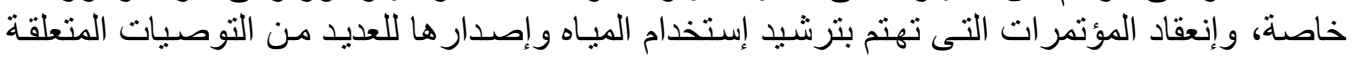

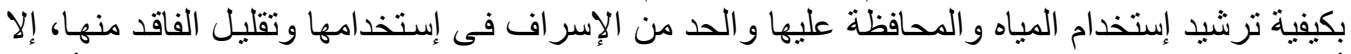

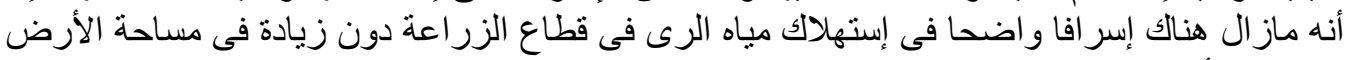

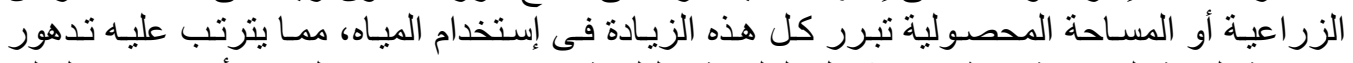

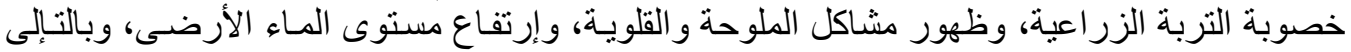

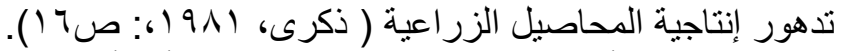

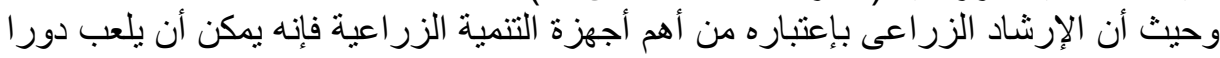

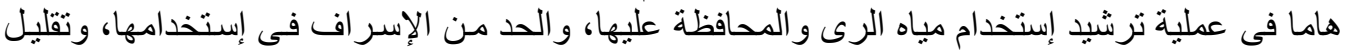

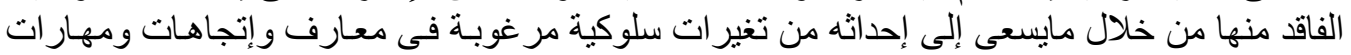

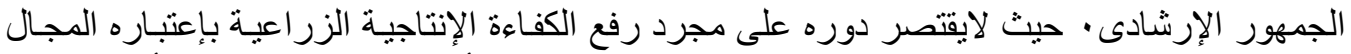

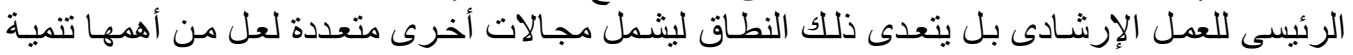

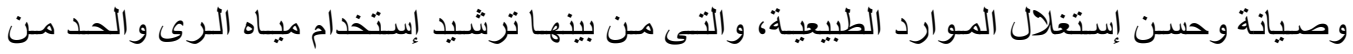

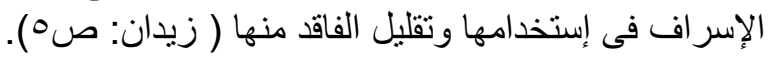

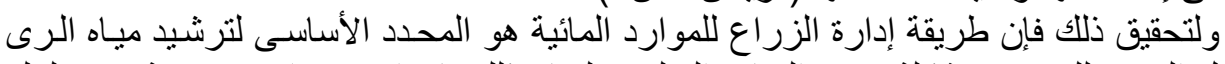

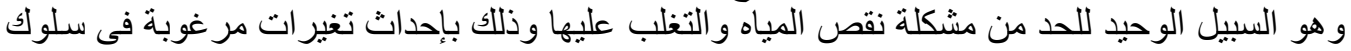

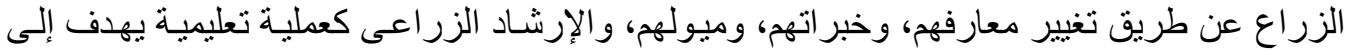

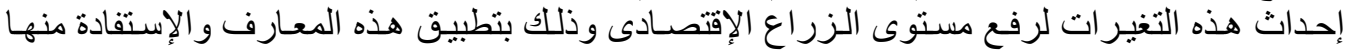

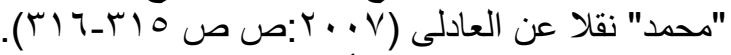

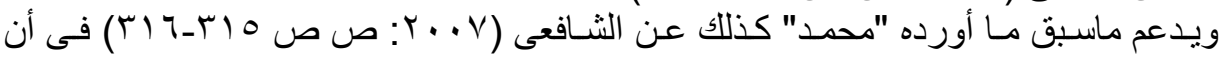

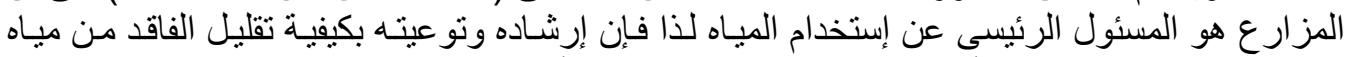

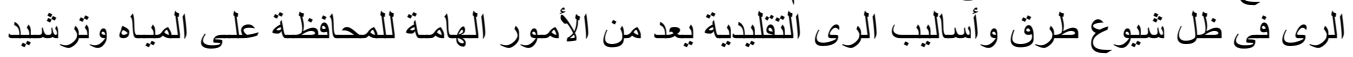

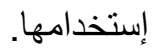

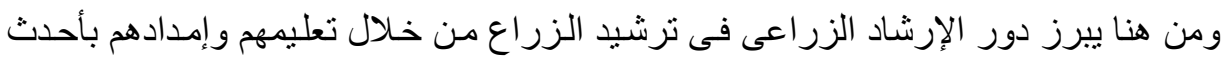

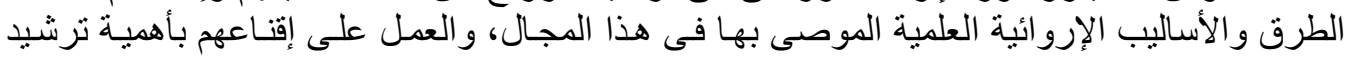
ولكل ما سبق فقد برزت الحاجة إلى ضرورة إجراء هذا البحث من أجل ترشيد إستخدام مياه

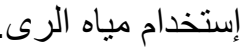

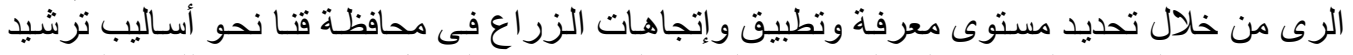

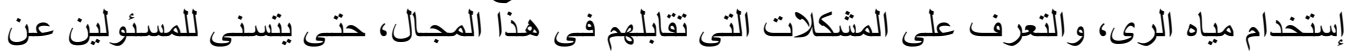

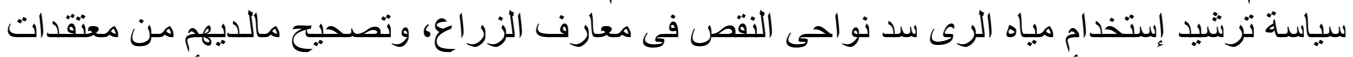

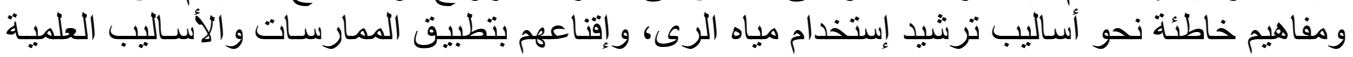

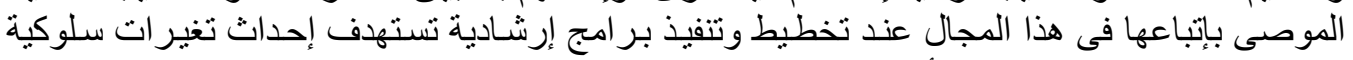

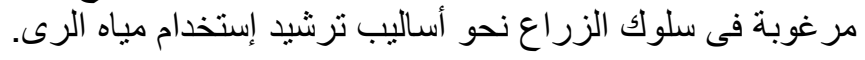

Fayoum J. Agric. Res. \& Dev., Vol. 27, No.2, July, 2014 


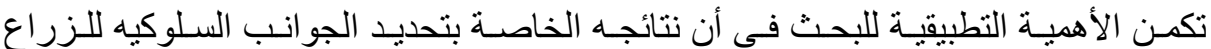

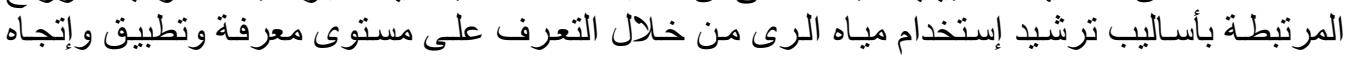

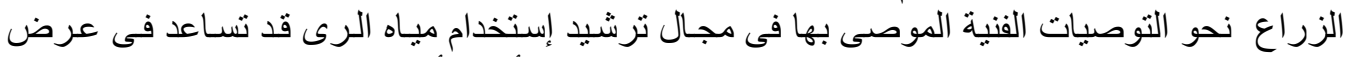

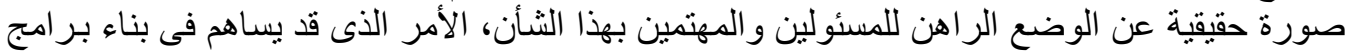

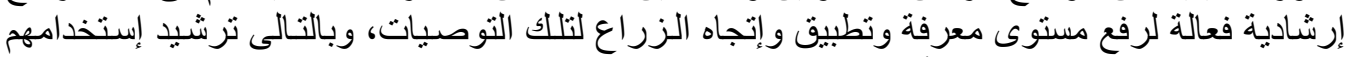

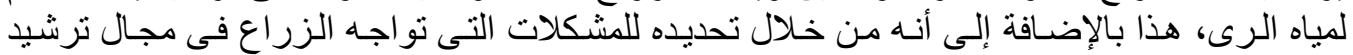

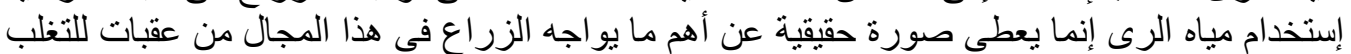

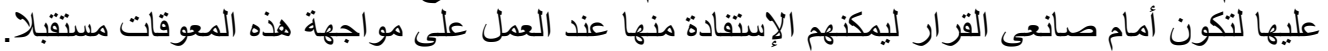

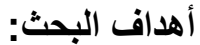

\section{وفقا للعرض المشكلى سالف الذكر أمكن تحديد أهداف البحث فيما يلى:}

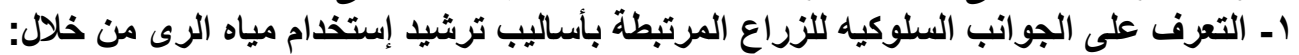

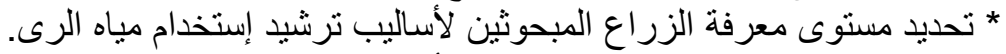

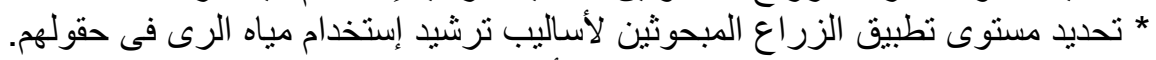

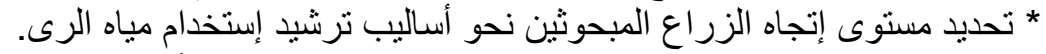

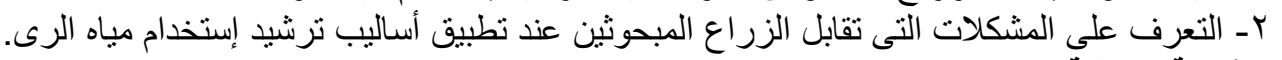

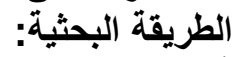

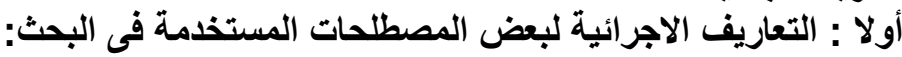

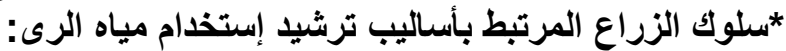

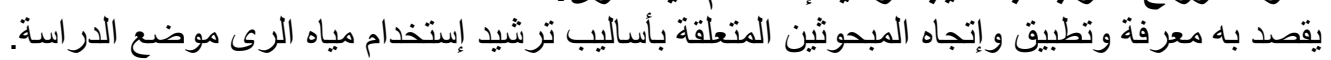

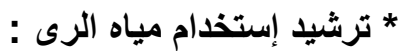

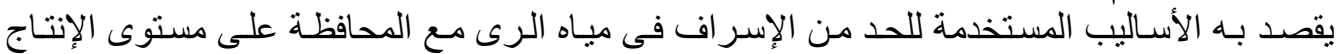
الزر اعى من أجل تحقيق أقصى إنتاجية زراعية بالنية الإسبة للوحدة الأرضية.

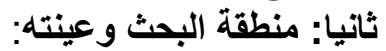

أجرى هذا البحث في محافظة فئنة قنا نظر الكونها إحدى المحافظـات الرئيسية المنتجـة للمحاصيل

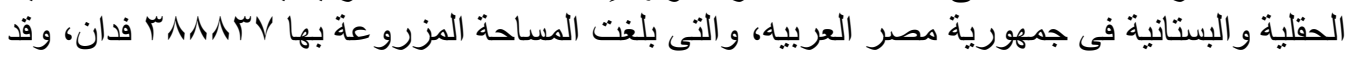

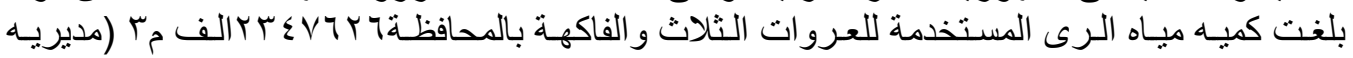

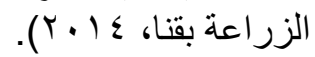

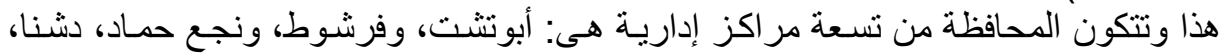

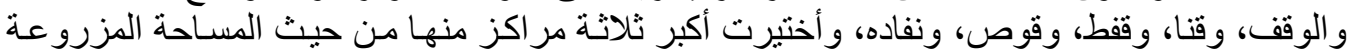

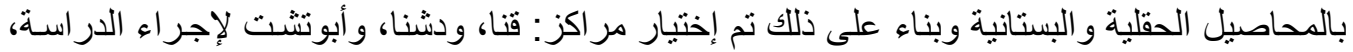

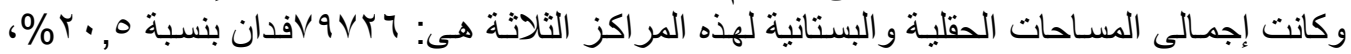

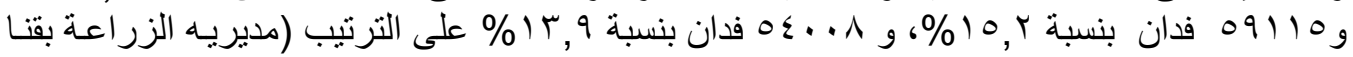
(r. $) \leqslant 。$

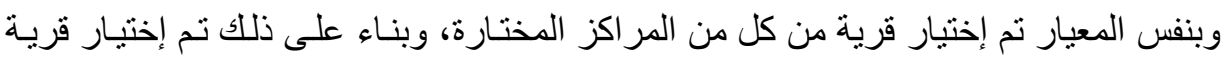

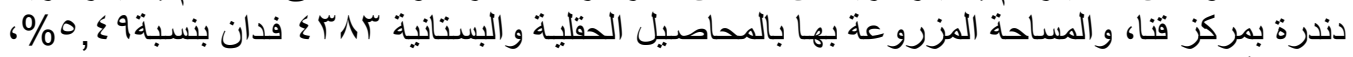

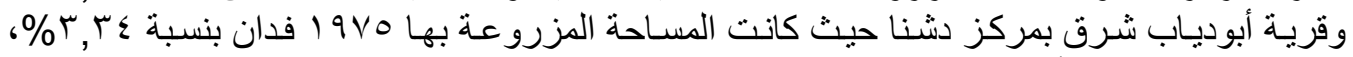

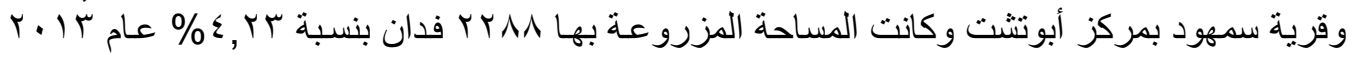

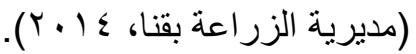
وللحصول على البيانات اللازمة لتحقيق أهداف البحث تم تحديد حجم عينة البحث طبقا لمعادلة

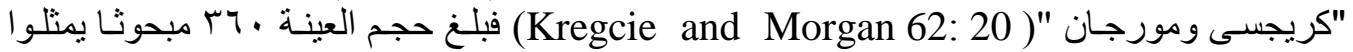

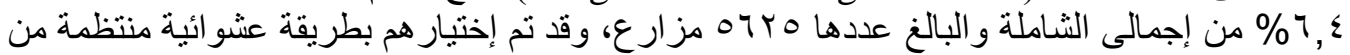

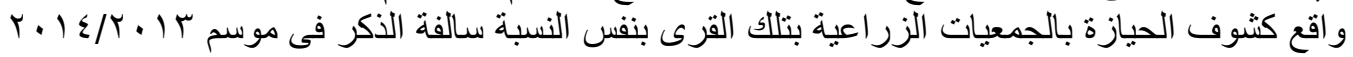

Fayoum J. Agric. Res. \& Dev., Vol. 27, No.2, July, 2014 
rr

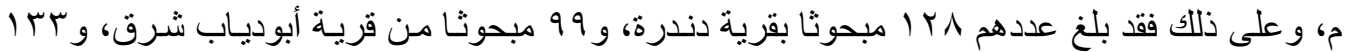

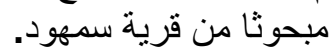

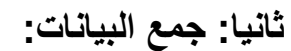

تم جمع البيانات البحثية بالمقابلة الثخصية للمبحوثين بإستخدام إستمارة الإستبيان والخاصـة

بالجوانب السلوكية للزر اع المرتبطة بأساليب ترشيد إستخدام مياه الرى، وقد إثنتملت على ثثلاثنة مقاييس منه إثنين لتحديد مستوى معرفة وتطبيت المبحوثين للممارسيات المتعلقة بأسـاليب ترشيد إستخدام ميـاه

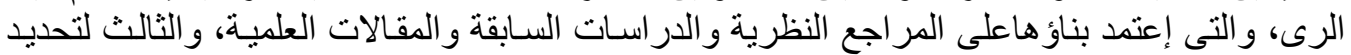

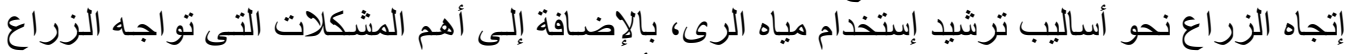

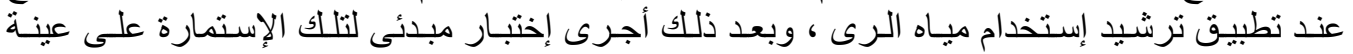

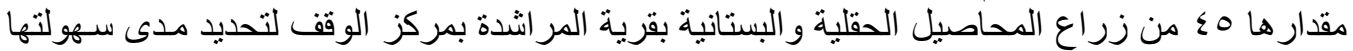

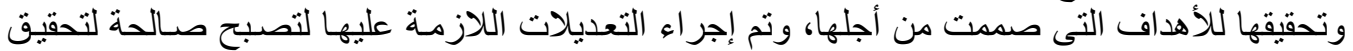

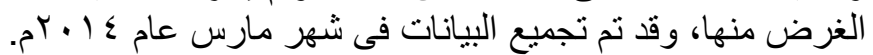
ثالثا: المعالجة الكمية للبيانات:

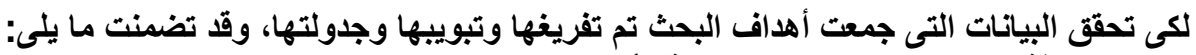

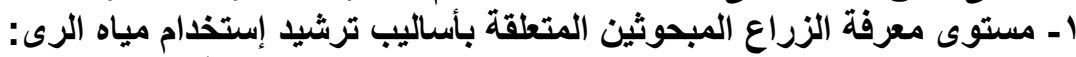

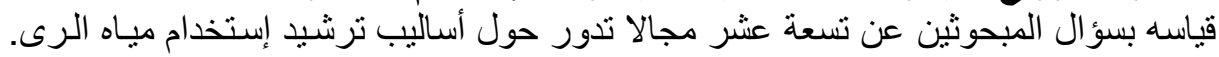

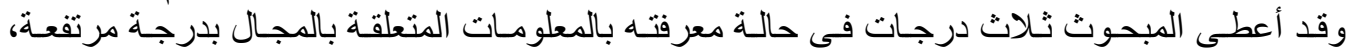

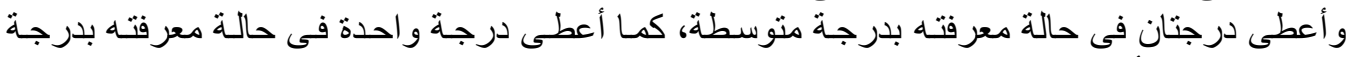

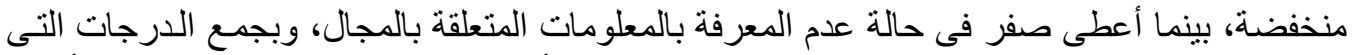

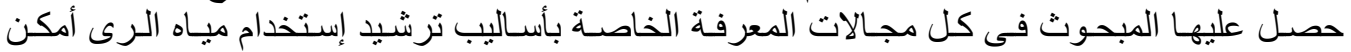

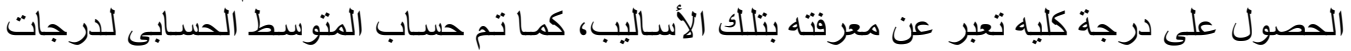

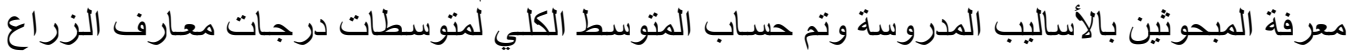

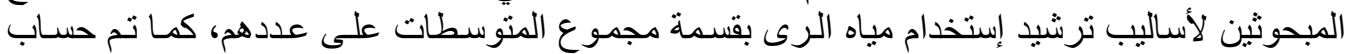

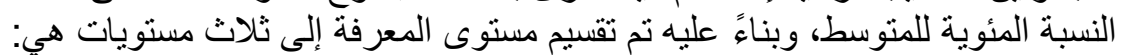

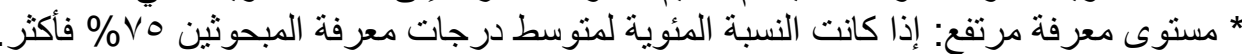

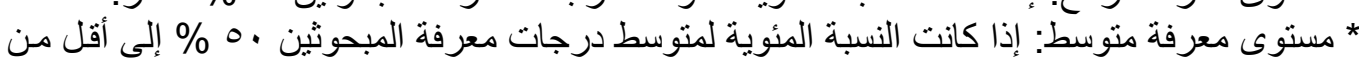
$\% \vee 0$

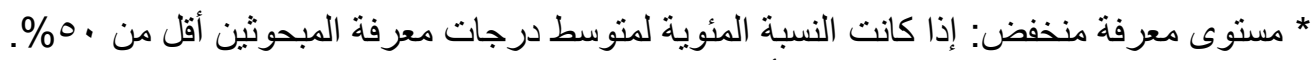

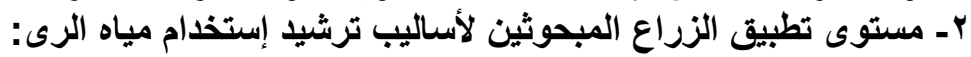

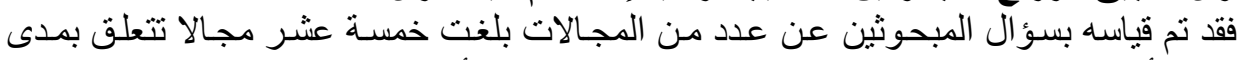

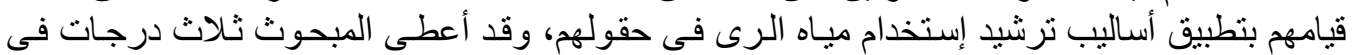

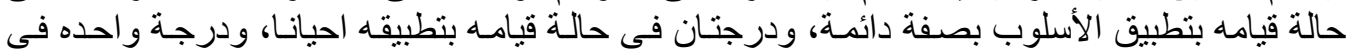

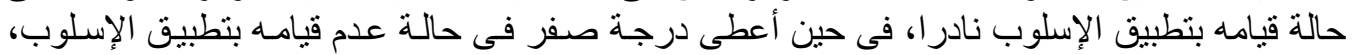

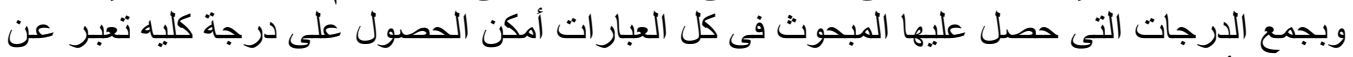

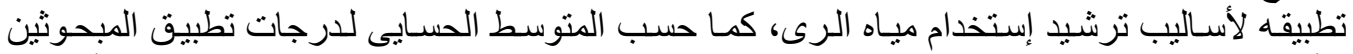

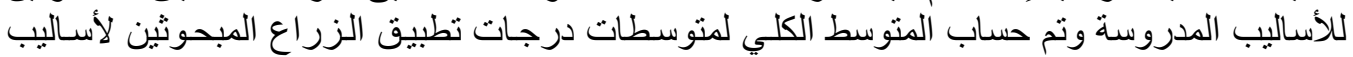

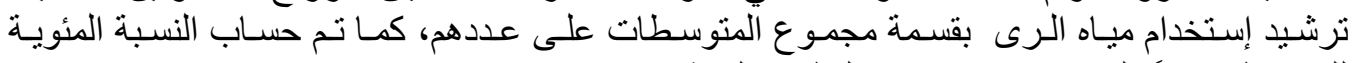

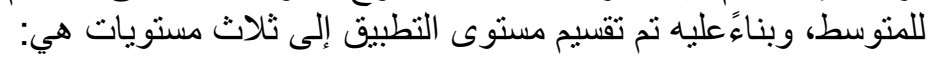

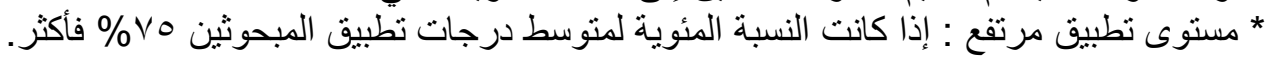

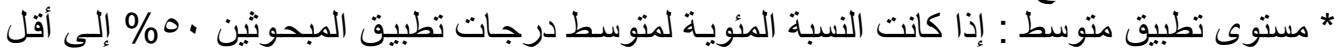

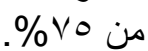

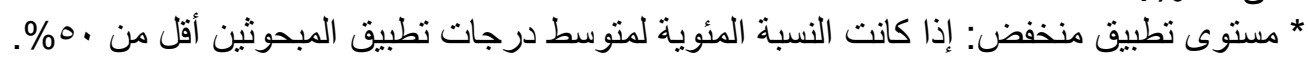
r- مستوى إتجاه الزراع نحو أساليب ترشيد إستخدام مياه الرىى:

Fayoum J. Agric. Res. \& Dev., Vol. 27, No.2, July, 2014 
rr

فقد قيس بمقيـاس تكـون فى صـورته النهائيـة مـن خمسـة عشـر عبـارة، سـبع عبـار ات منهـا

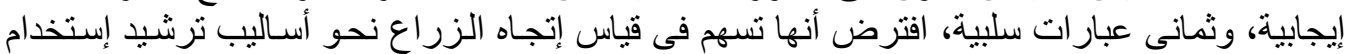

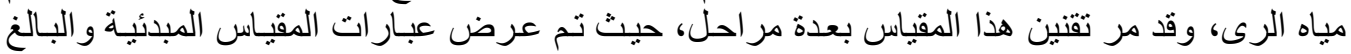

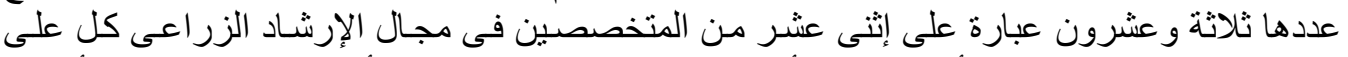

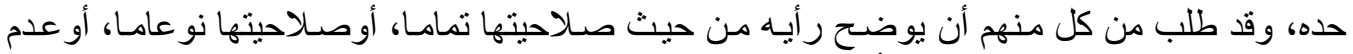

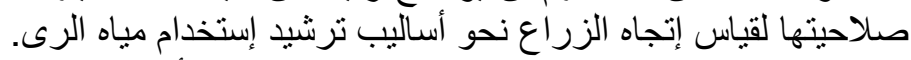

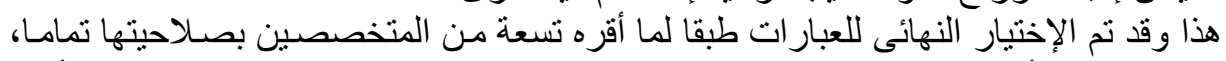

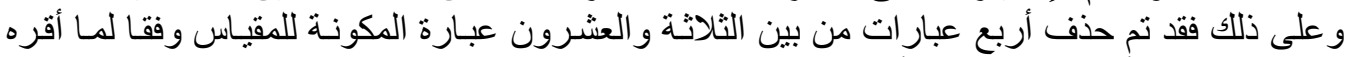

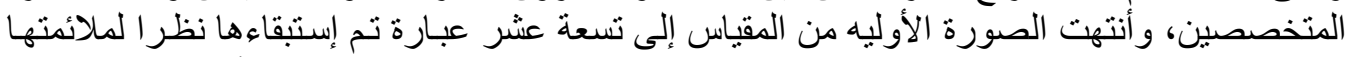

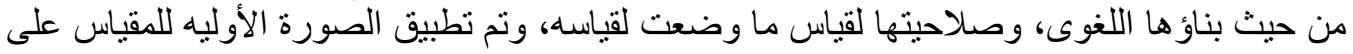

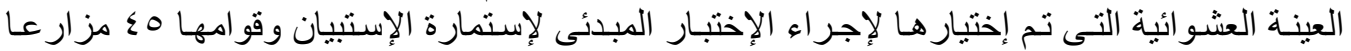

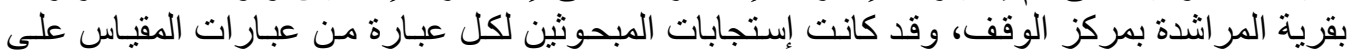

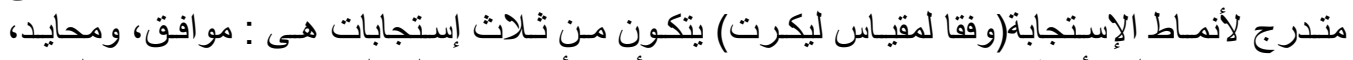

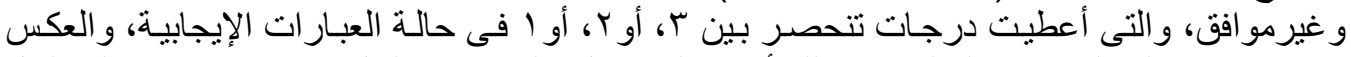

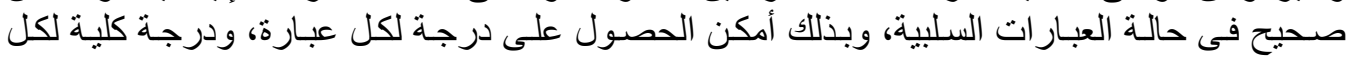

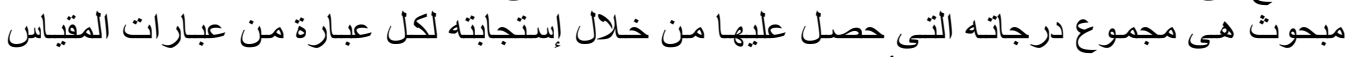
و التى تعبر عن درجة إتجاهـ نحو أساليب ترشيد إستخدام مياه الرى، وبإستخر اج معاملات الإرتباط بين

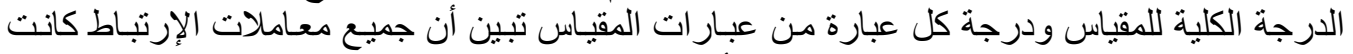

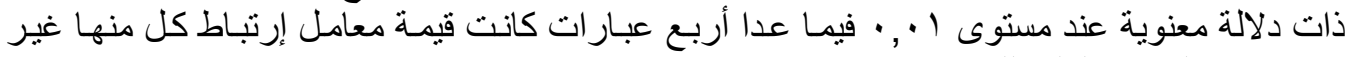

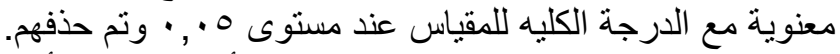

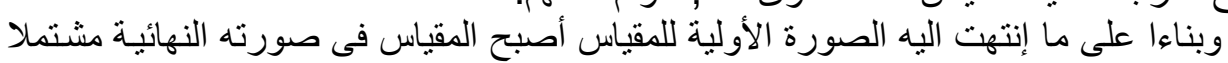

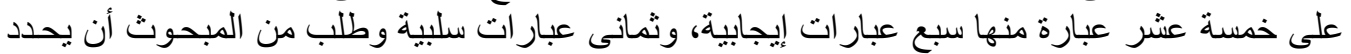

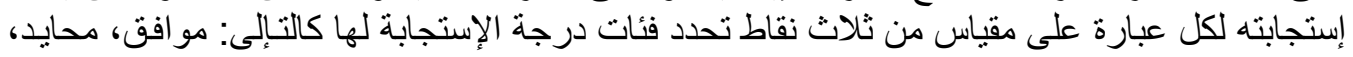

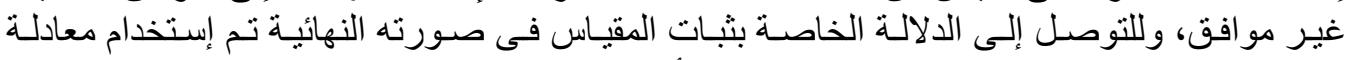

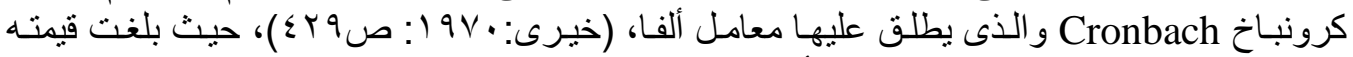

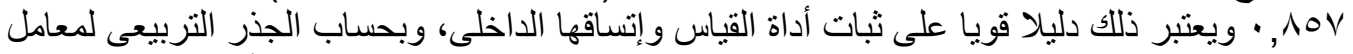

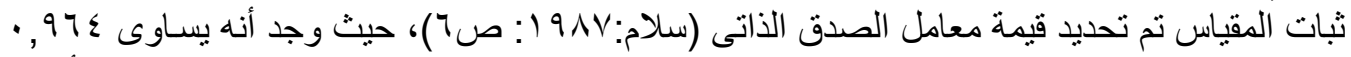

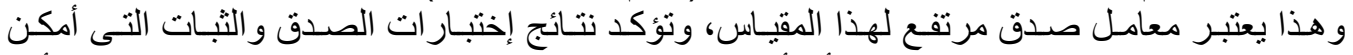

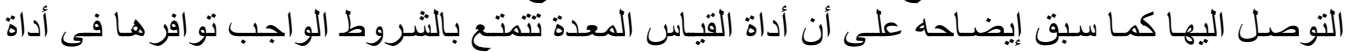

القياس المناسبة و الموثوقة الئة ملحق رقم (1) (1).

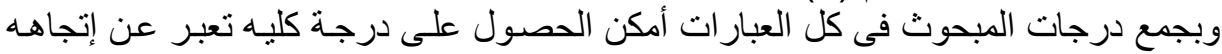

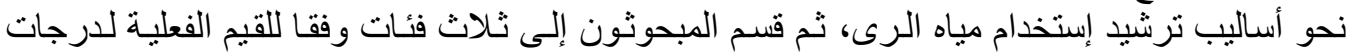

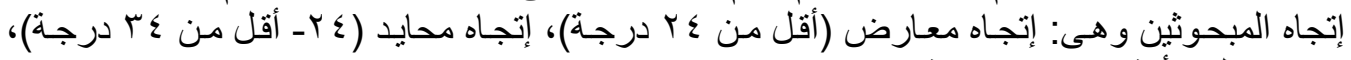

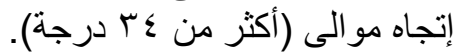

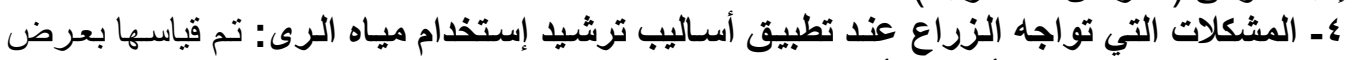

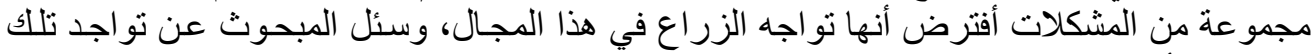

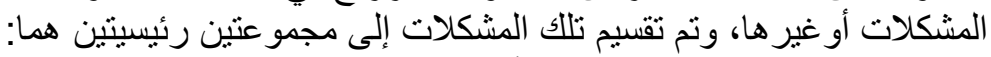

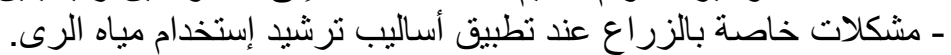

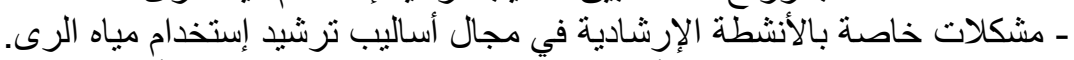

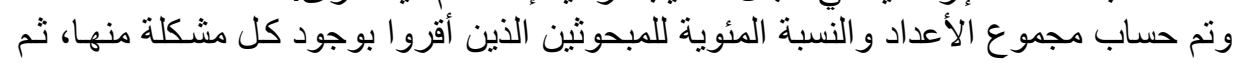

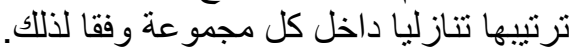

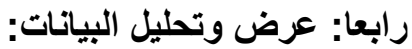

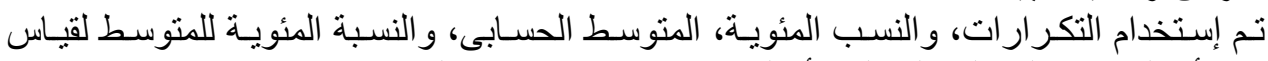
المؤشر ات أو الجوانب المختلفة المتعلقة بأساليب ترشيد إستخدام مياه الرىى.

Fayoum J. Agric. Res. \& Dev., Vol. 27, No.2, July, 2014 


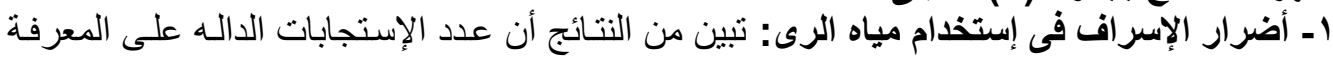

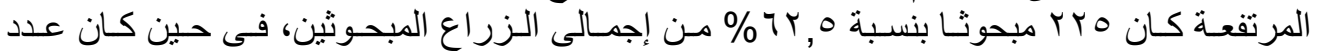

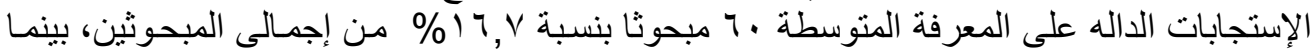

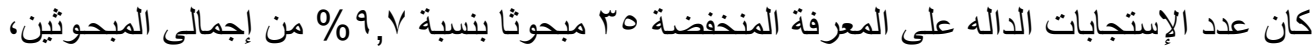

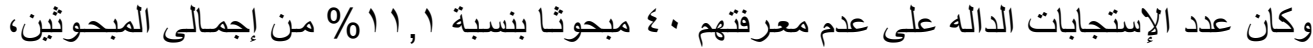

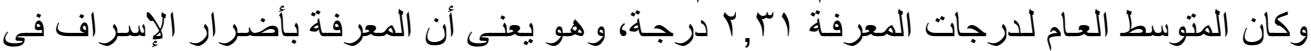

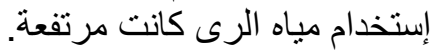

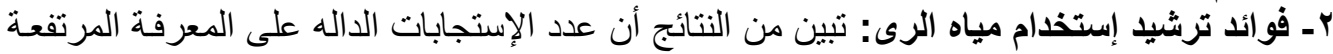

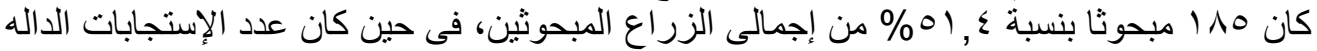

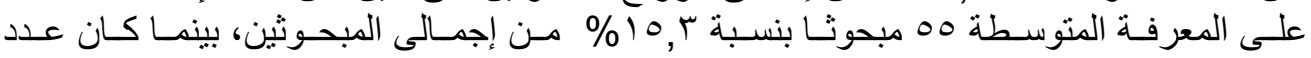

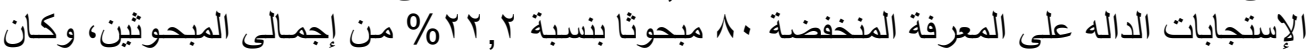

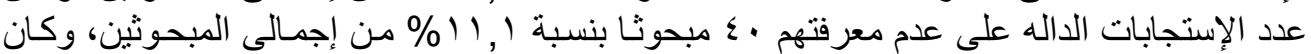

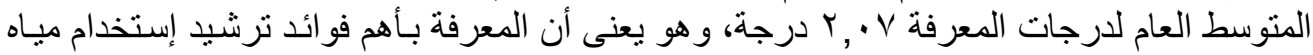
الرى كانت مرتفعة.

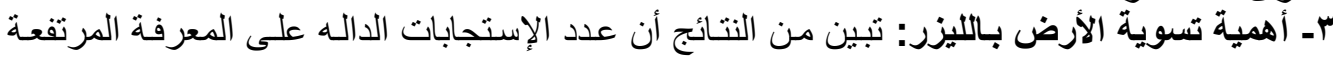

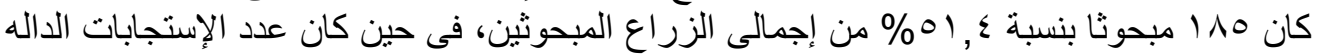

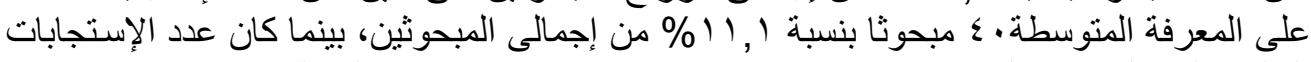

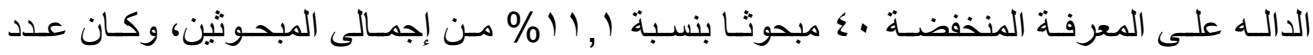

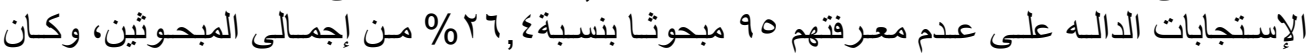

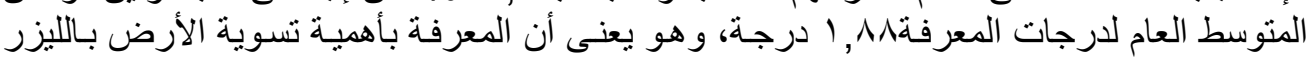

كانت منوسطة.

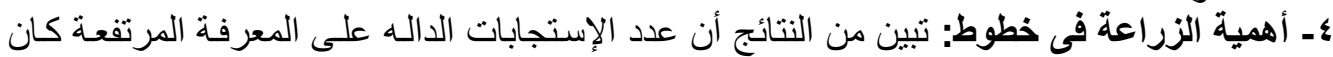

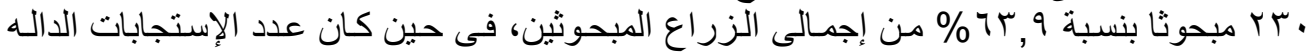

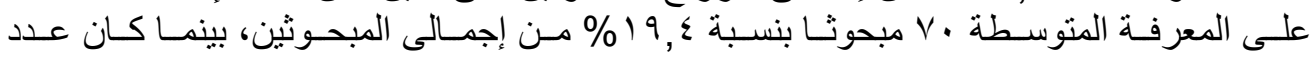

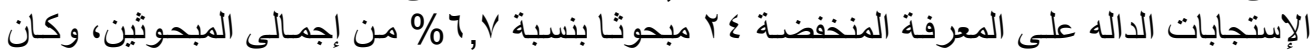

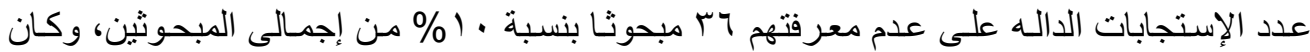

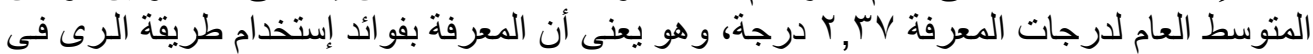
خطوط كانت مرتفعة.

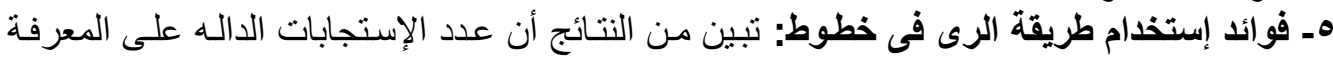

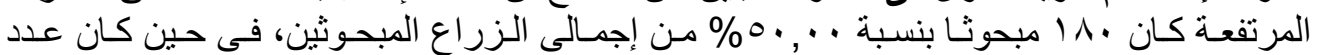

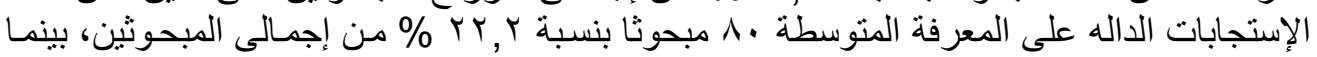

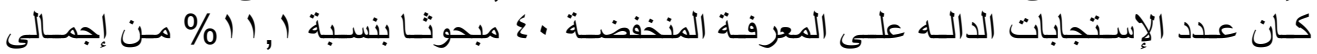

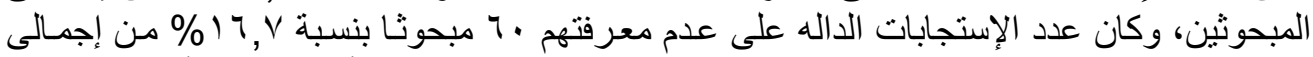

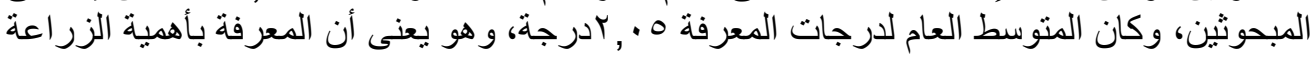
في خطوط كانت مرتفعة.

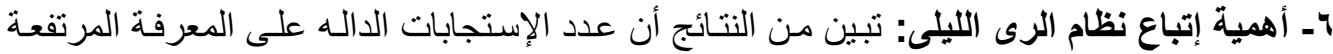

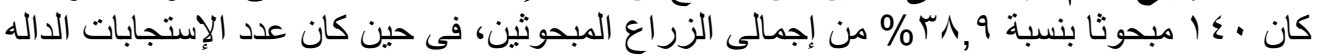

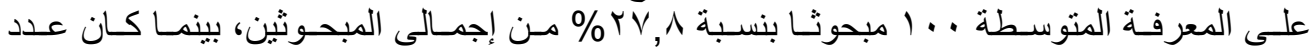

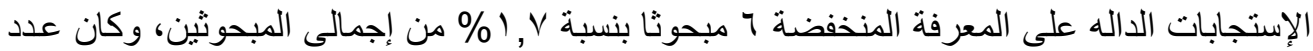

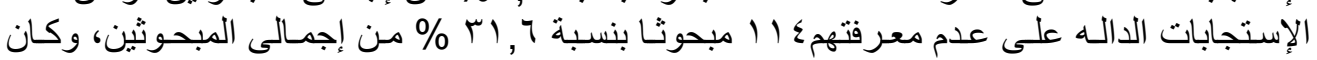

Fayoum J. Agric. Res. \& Dev., Vol. 27, No.2, July, 2014 
المتوسط العام لدرجات المعرفة او9, ، درجة، و هو بعنى أن المعرفـة بأهمية إتبـاع نظـام الرى الليلى

كانت منخفضة.

Vـ أهمية تطهير المساقى الحقلية: تبين من النتائج أن عدد الإستجابات الدالـه على المعرفة المرتفعـة

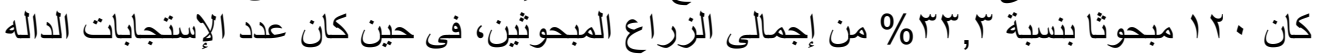

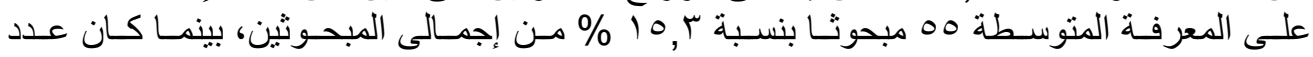

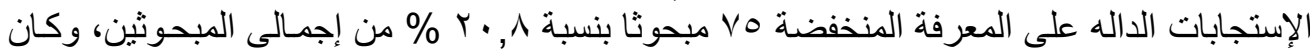

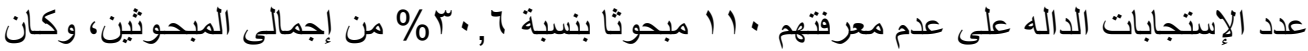

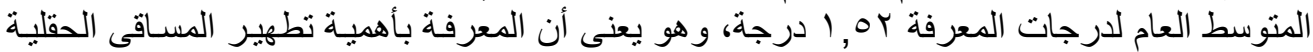

كانت متوسطة.

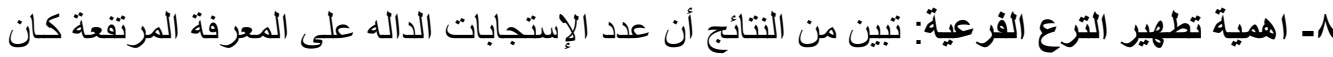

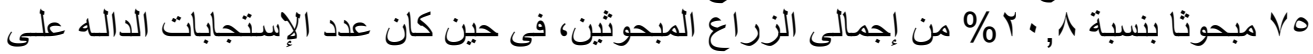

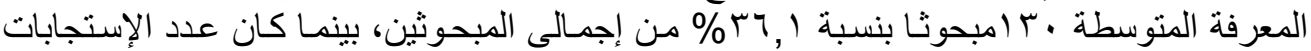

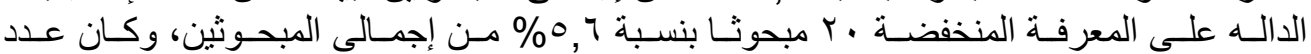

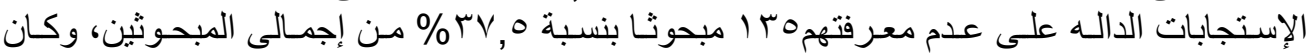

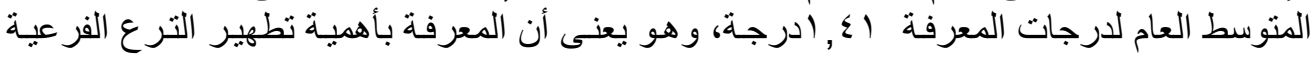
كانت منوسطة.

9ـ أهمية تبطين المساقى الحقلية بالخرسانة: تبين من النتائج أن عدد الإستجابات الداله على المعرفة

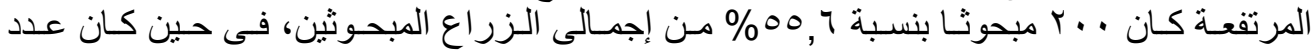

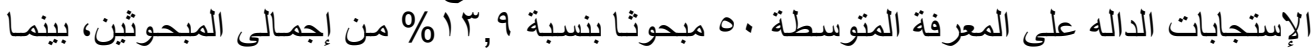

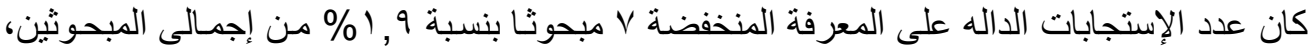

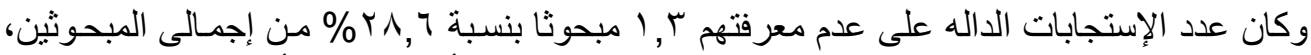

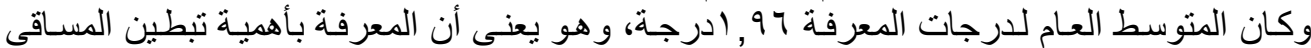

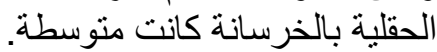

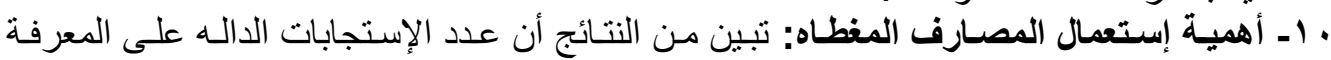

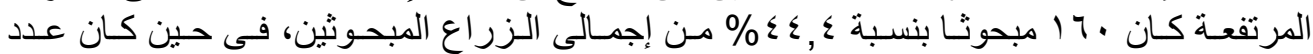

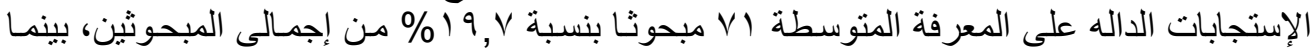

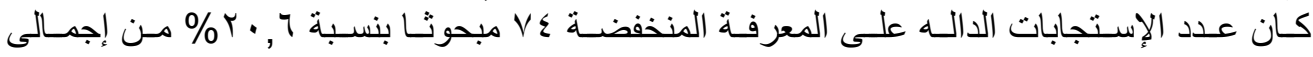

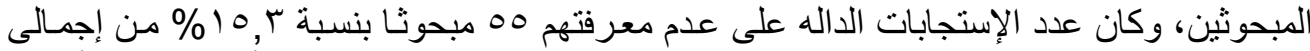

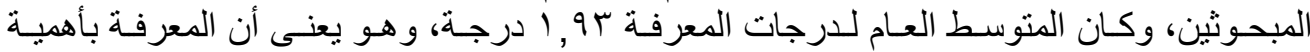

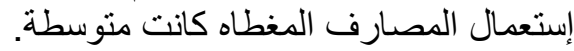

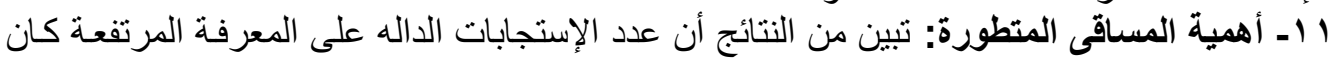

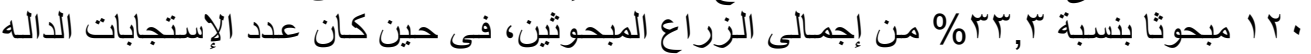

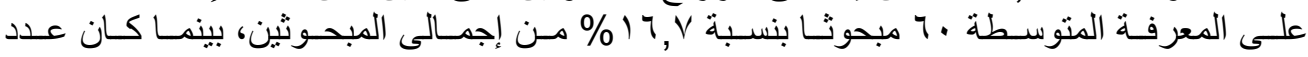

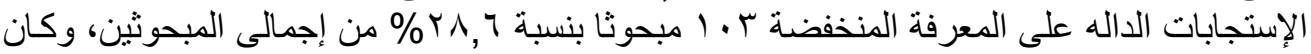

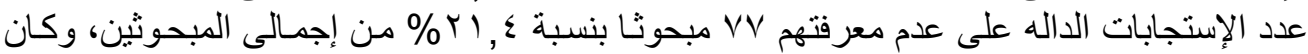

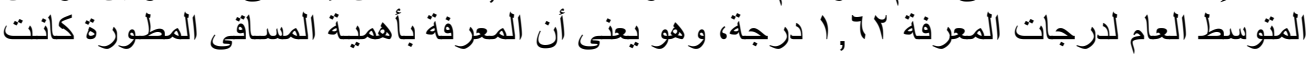
متوسطة.

r ا ـ فائدة الحرث تحث التربة: تبين من النتائج أن عدد الإستجابات الداله على المعرفة المرتفعة كان

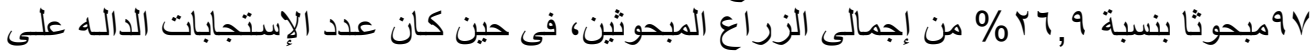

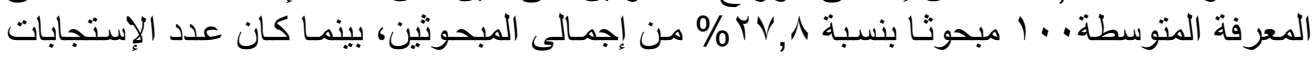

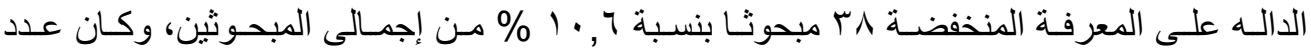

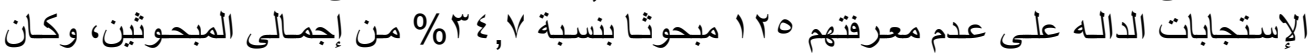

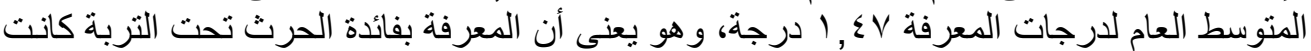
متوسطة.

Fayoum J. Agric. Res. \& Dev., Vol. 27, No.2, July, 2014 
ry

ب ا ـ أضرار إستخدام الرى بالغمر: تبين من النتائج أن عدد الإسـتجابات الدالـه على المعرفة المرتفعـة

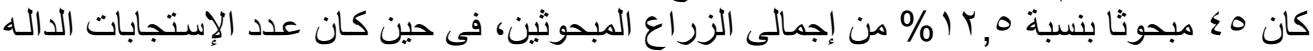

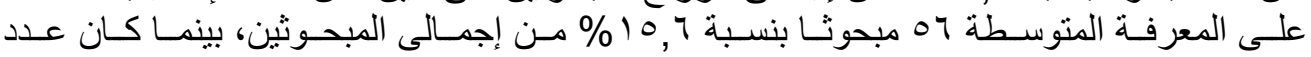

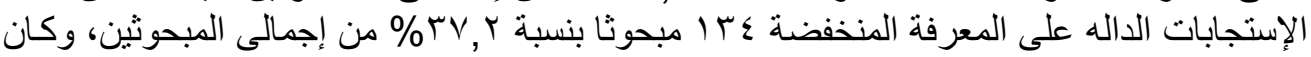

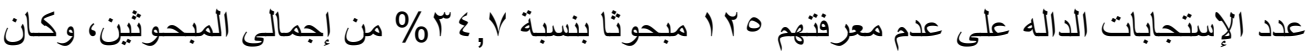

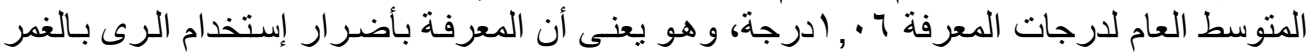
كانت متوسطة.

ع اـ فائدة إسـتخدام نظـام الـرى بـالرفع: تبـين مـن النتـائج أن عدد الإسـتجابات الدالـه على المعرفـة

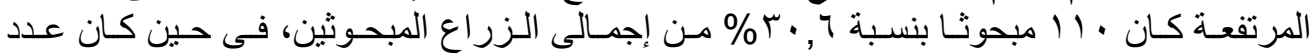

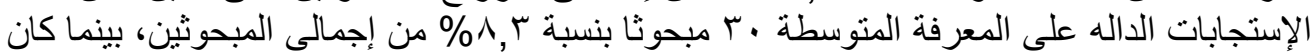

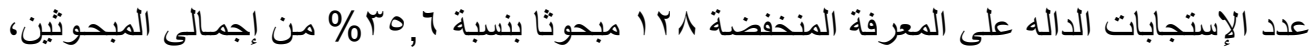

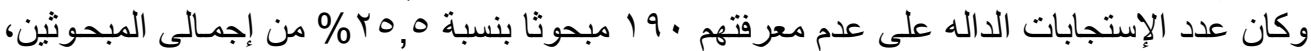

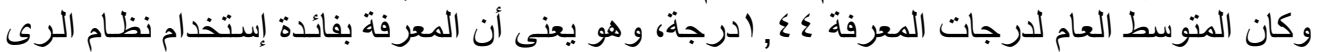
بالرفع كانت متوسطة. ه ا ـ فوائد إستخدام وسـائل الرى الحديثة: تبين من النتائج أن عدد الإستجابات الداله على المعرفة

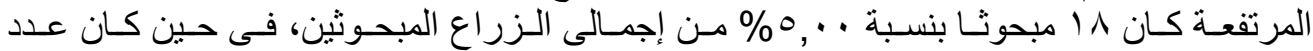

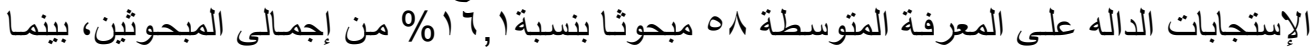

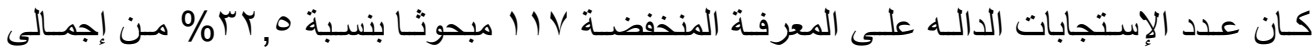

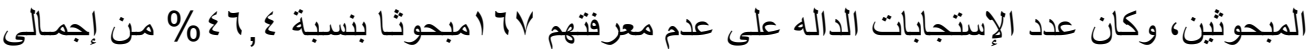

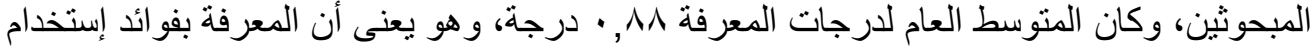

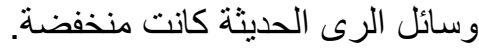

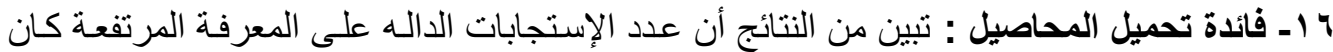

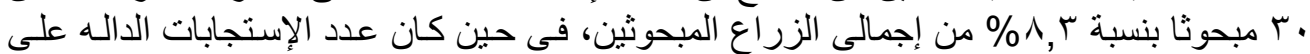

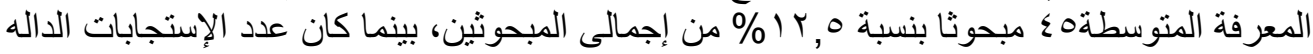

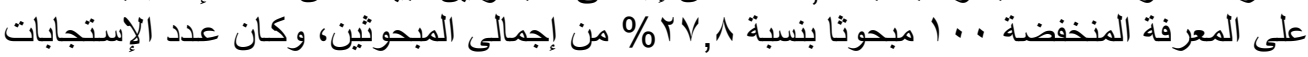

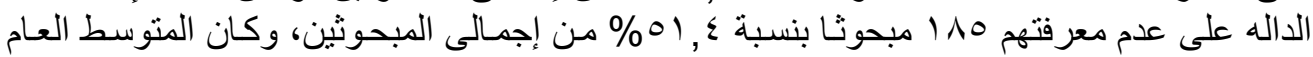

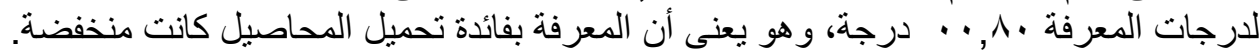

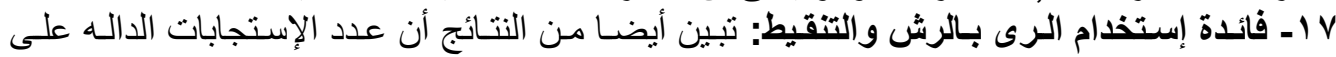

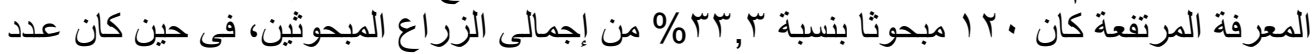

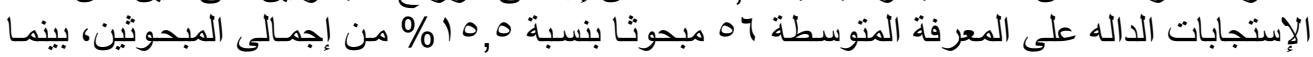

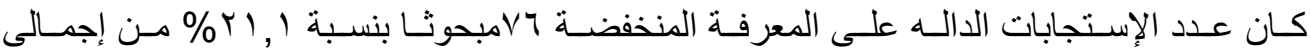

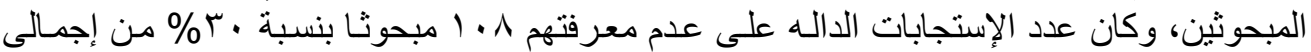

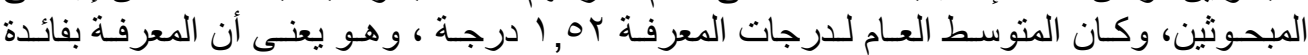

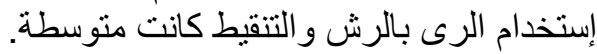

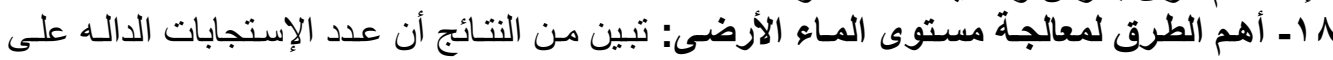

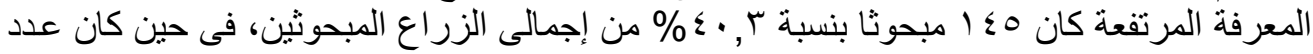

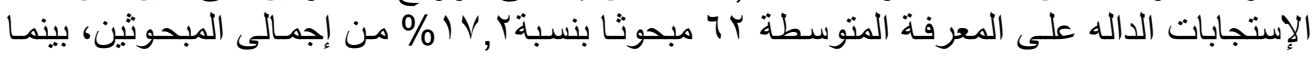

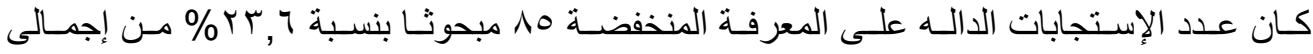

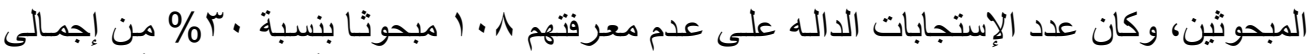

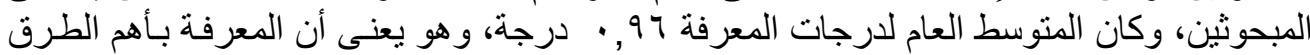

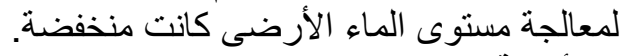

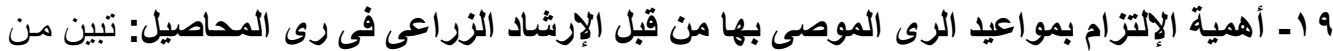

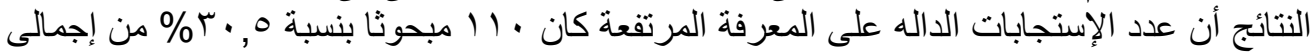

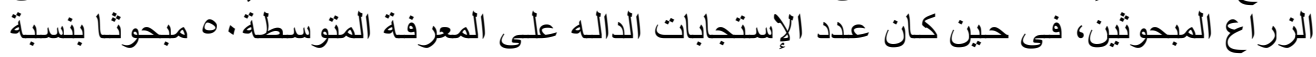

Fayoum J. Agric. Res. \& Dev., Vol. 27, No.2, July, 2014 
rV

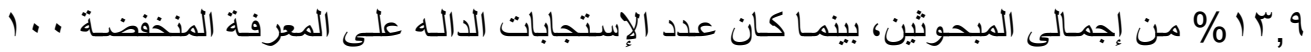

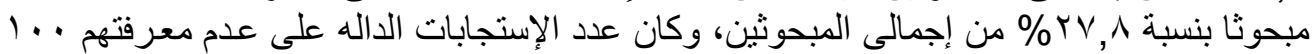

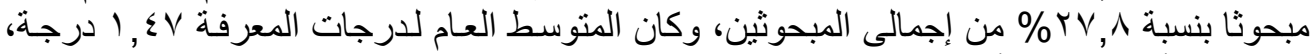

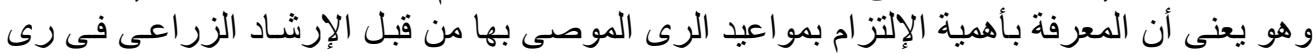
المحاصيل كانت منوسطة.

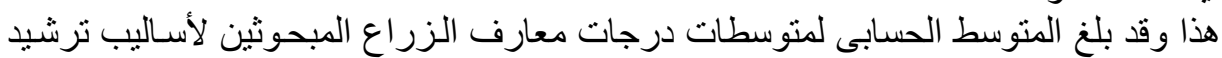

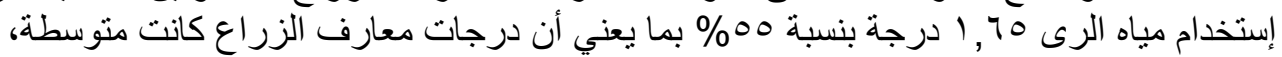

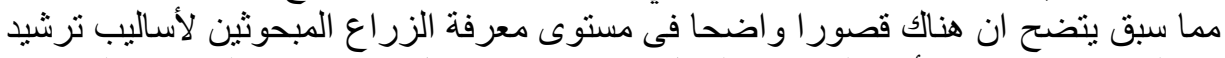

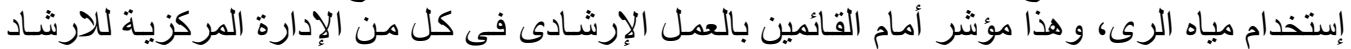

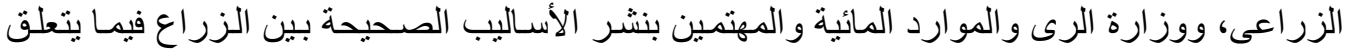

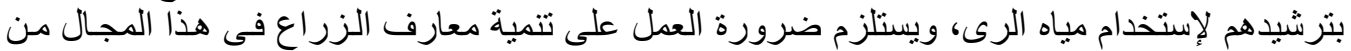

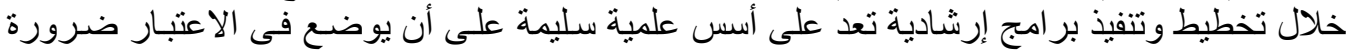

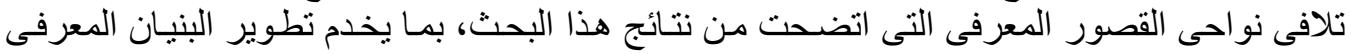

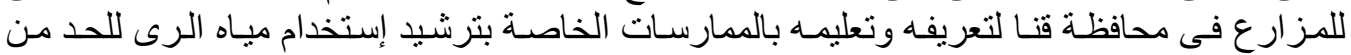

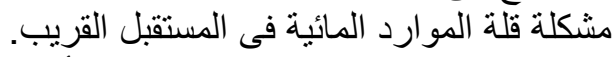

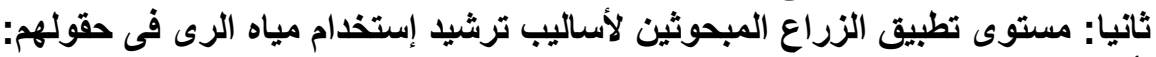

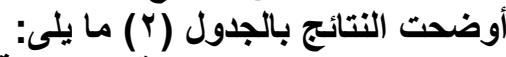

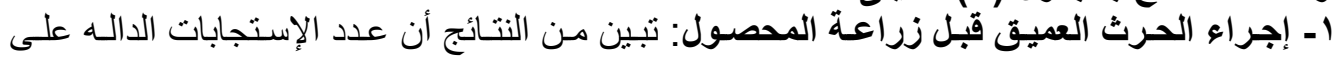

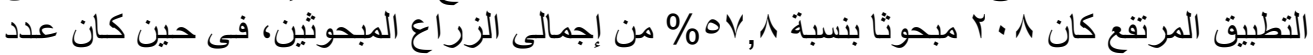

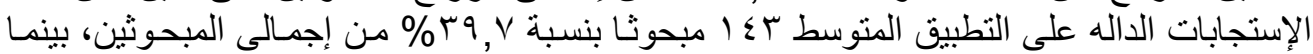

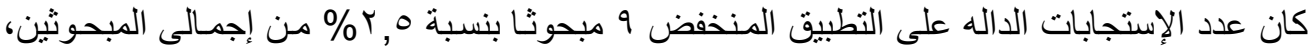

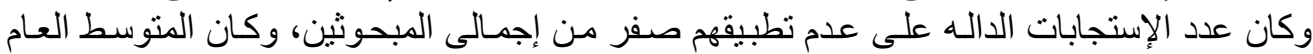

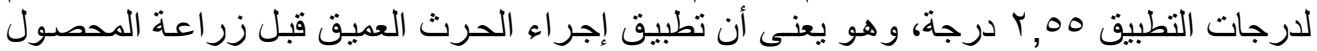
كان مرتفعا.

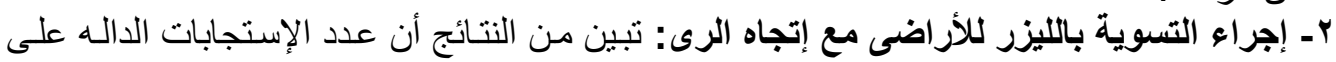

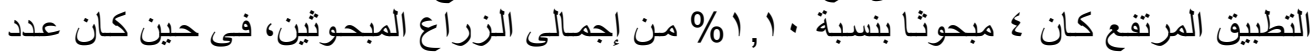

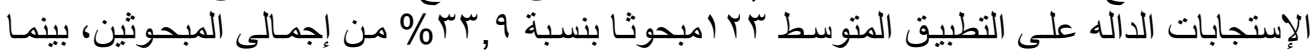

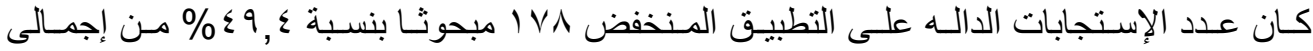

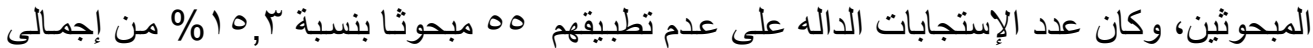

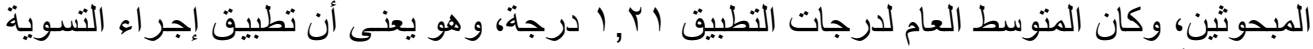

$$
\text { بالليزر للأر اضى معان مع إتجاه الرى كام كان منوسطا. }
$$

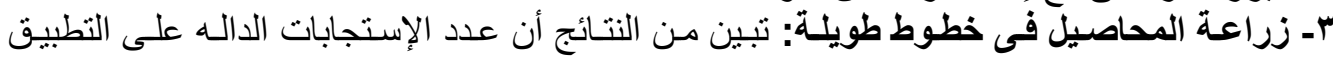

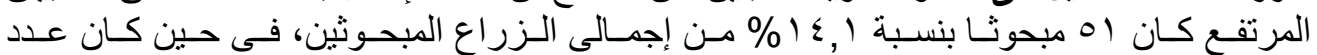

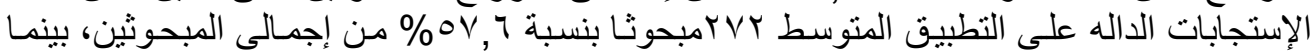

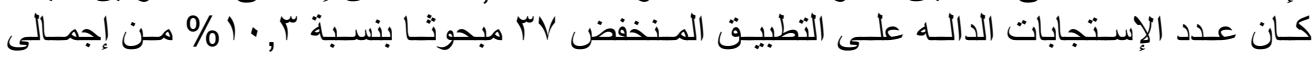

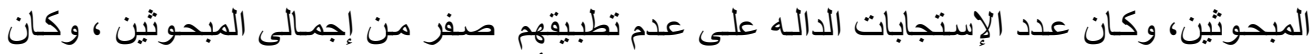

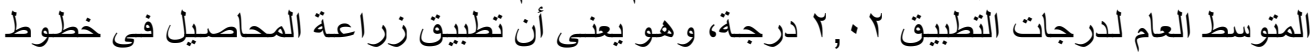
طويلة كان مرتفعا.

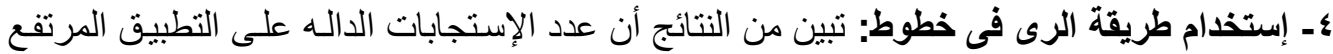

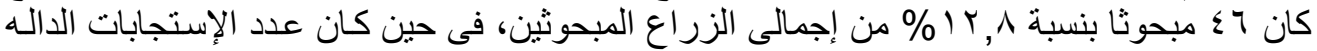

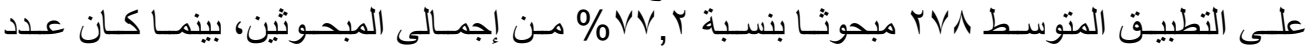

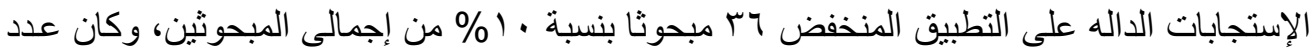

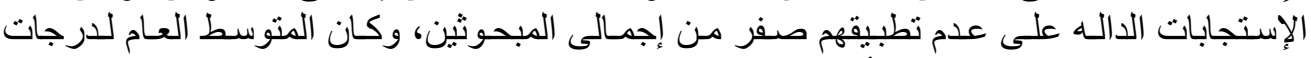

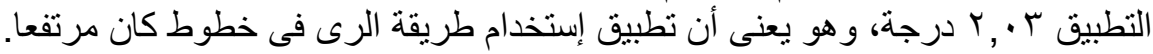

Fayoum J. Agric. Res. \& Dev., Vol. 27, No.2, July, 2014 


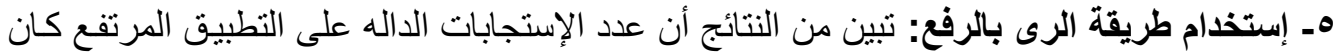
ع TrV

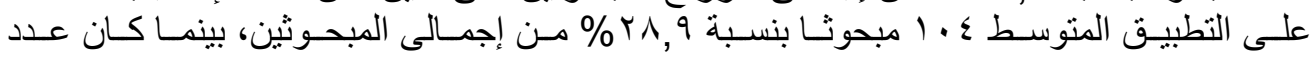

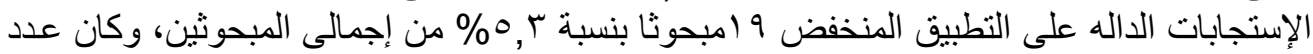

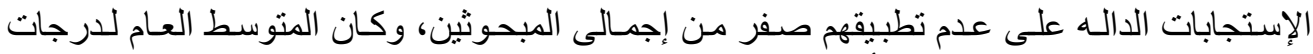

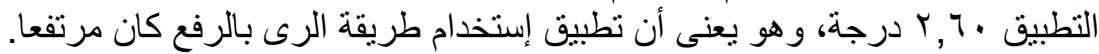

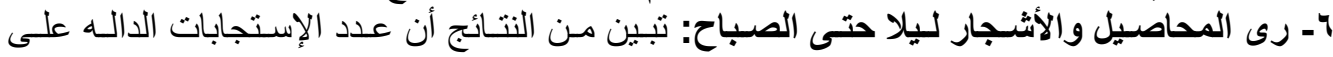

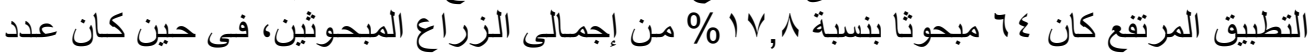

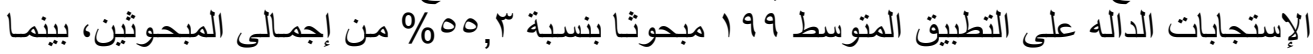

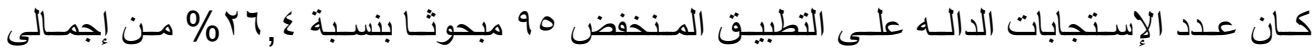

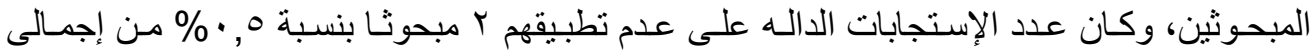

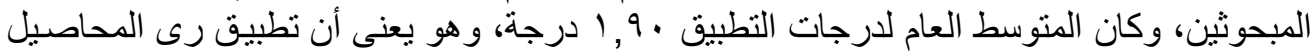

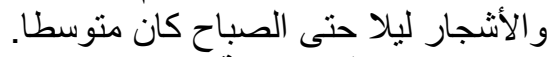

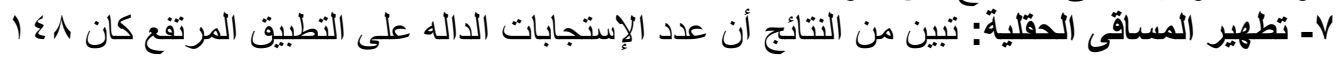

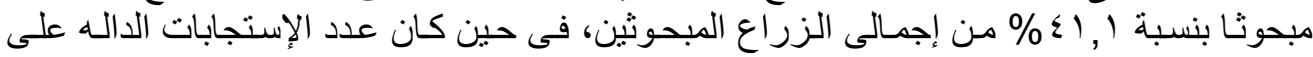

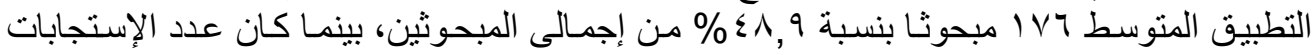

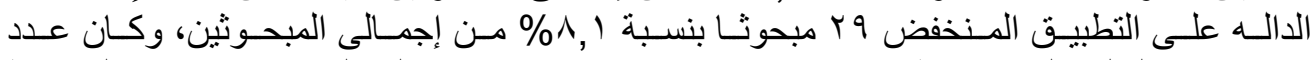

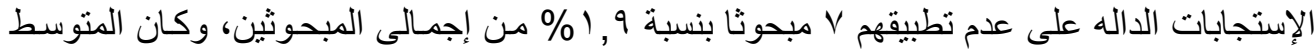

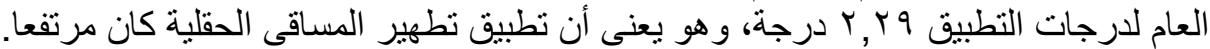

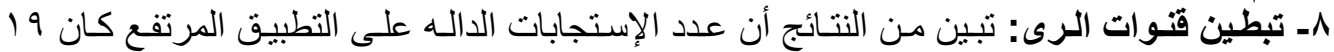

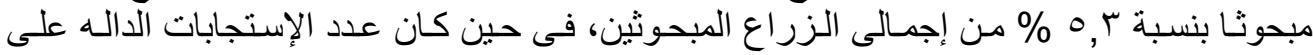

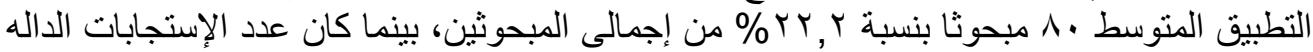

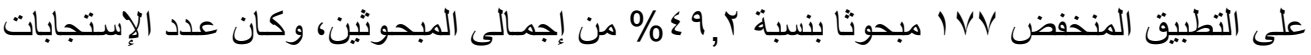

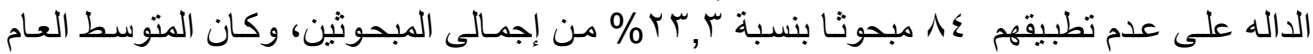

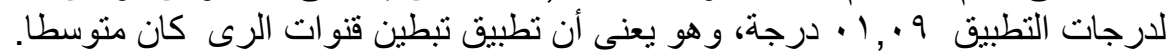

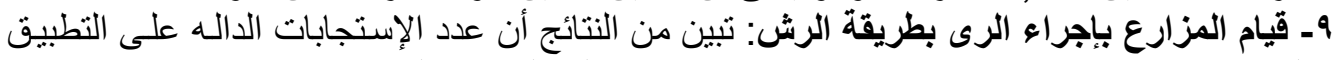

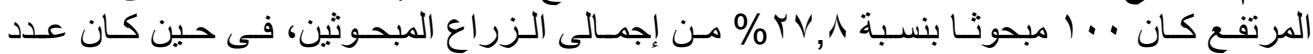

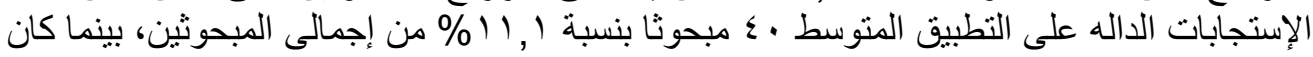

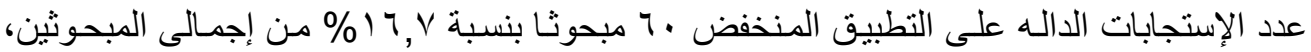

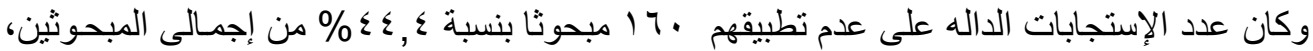

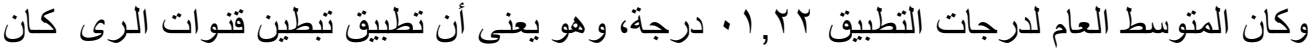

متوسطا.

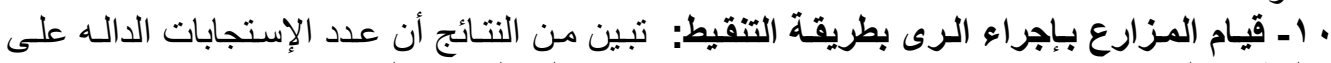

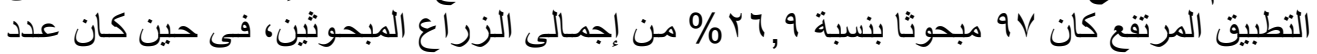

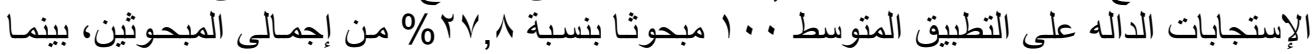

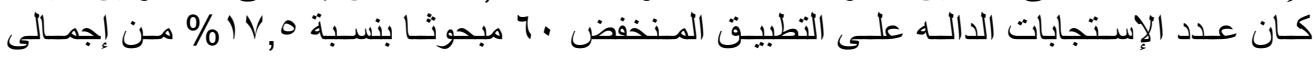

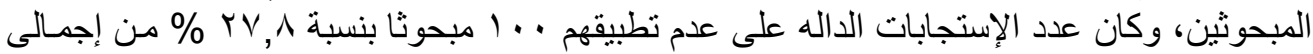

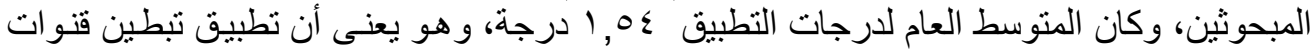
الرى كان متوسطا.

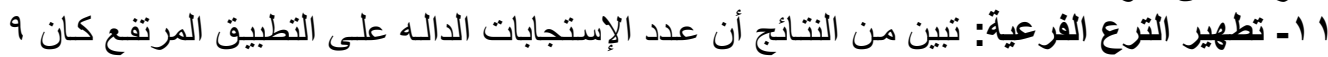

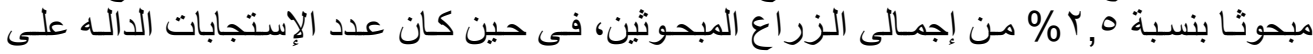

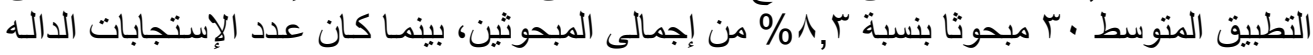

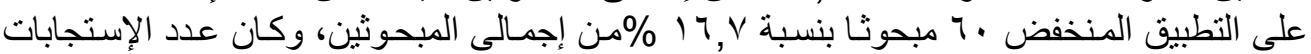

Fayoum J. Agric. Res. \& Dev., Vol. 27, No.2, July, 2014 
rq

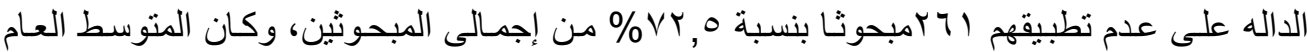

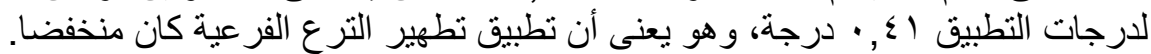

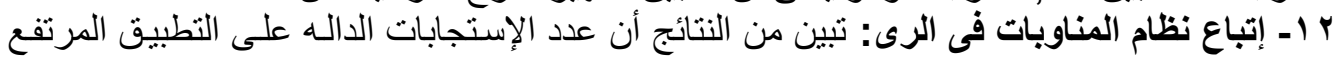

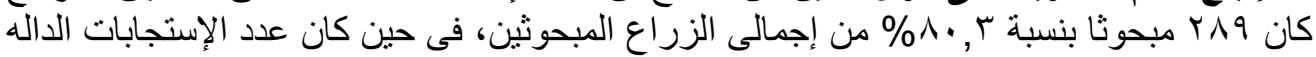

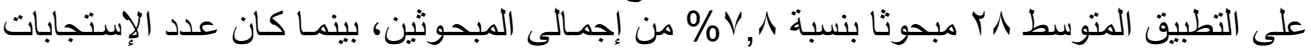

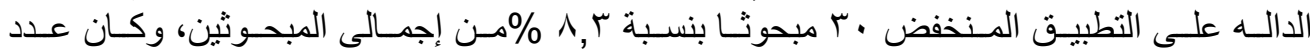

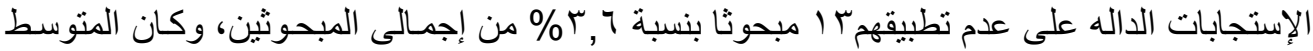

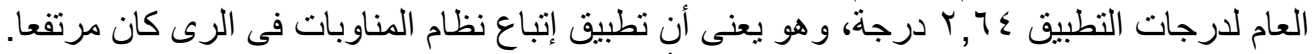

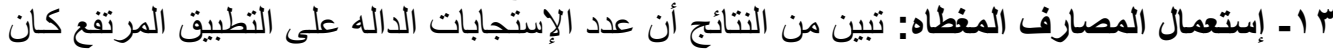

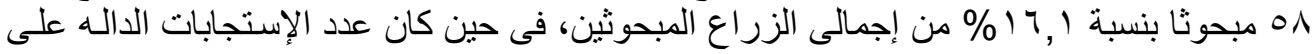

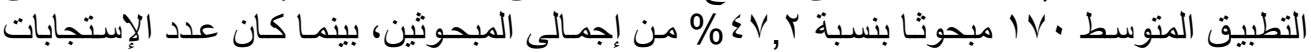

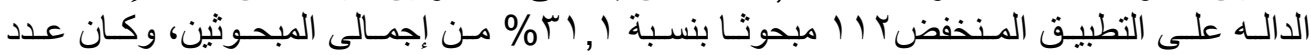

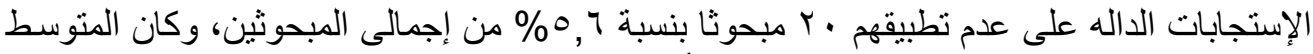

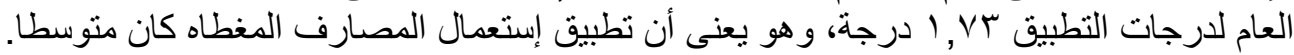

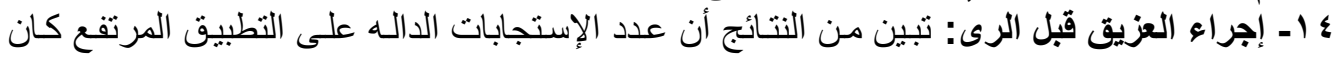

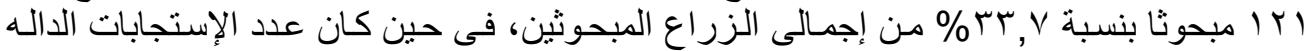

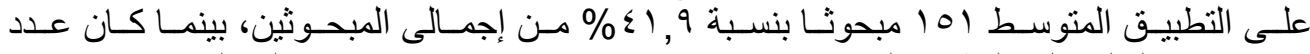

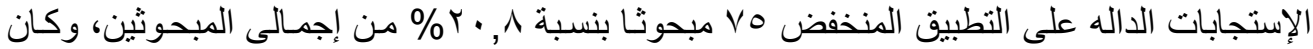

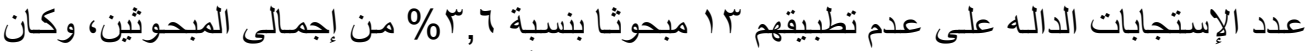

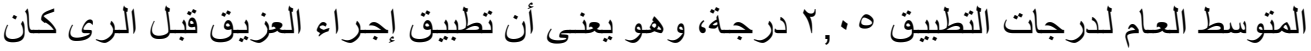

1 ـ ـ تحميل محصول على محصول أخر: تبين من النتائج أن عدد الإستجابات الداله على التى التطبيق

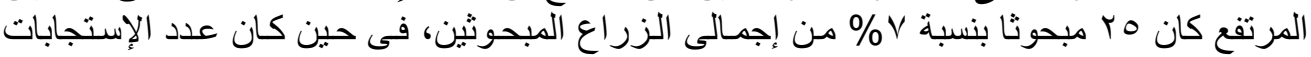

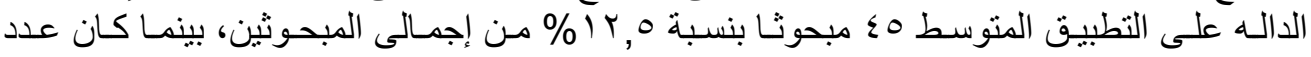

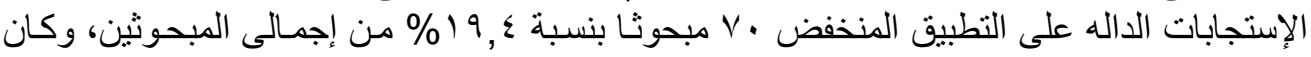

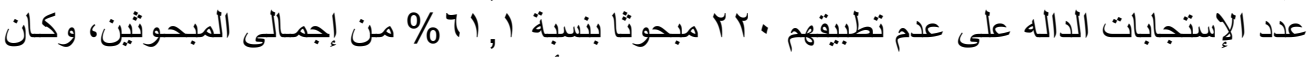

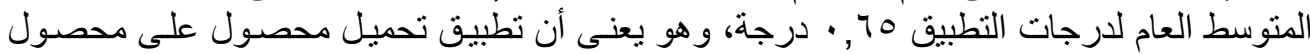
أخر كان منخفضا.

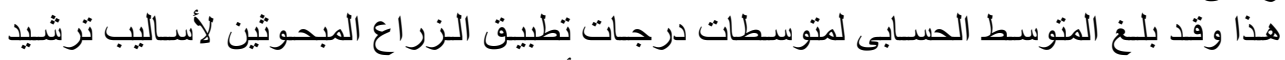

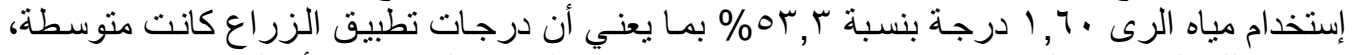

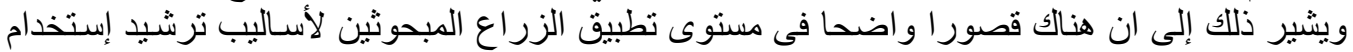

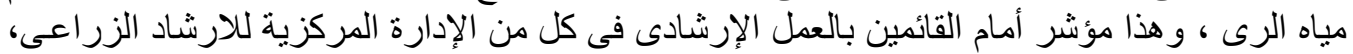

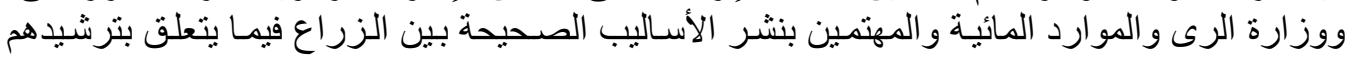

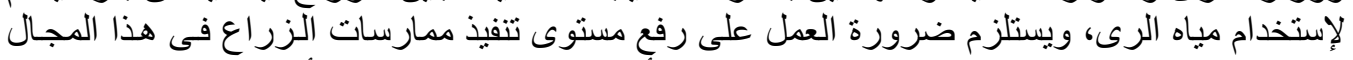

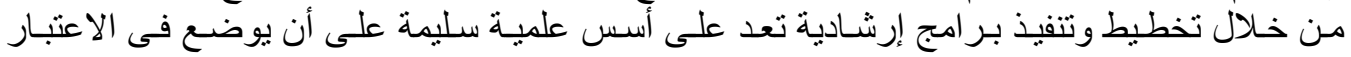

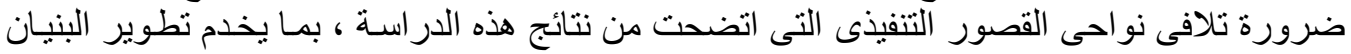

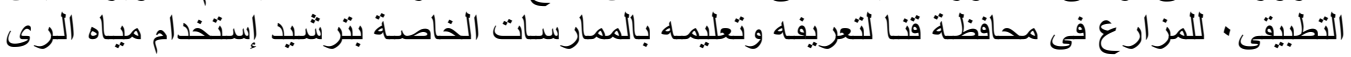

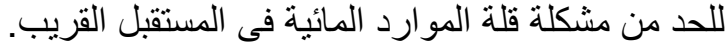

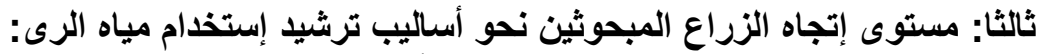

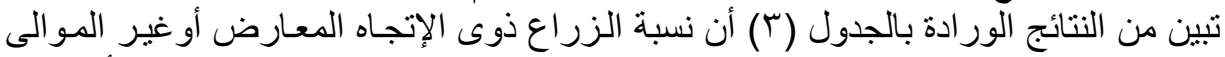

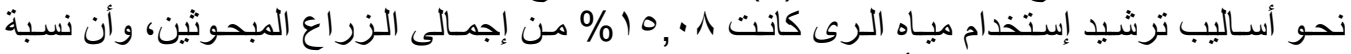

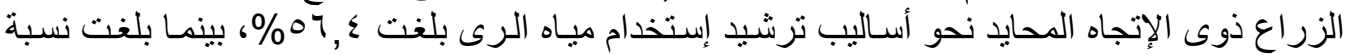

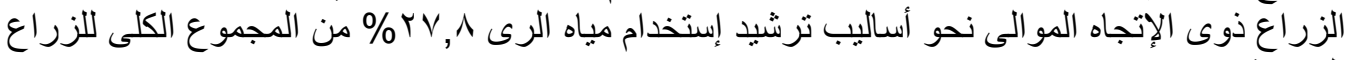

Fayoum J. Agric. Res. \& Dev., Vol. 27, No.2, July, 2014

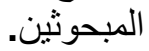


$r$.

ومن العرض السابق يتضح أن هنالك نسبة لايستهان بها من إجمالى عدد الزراع المباع المبحوثين

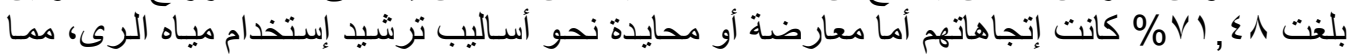

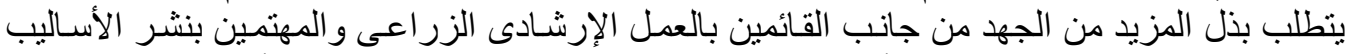

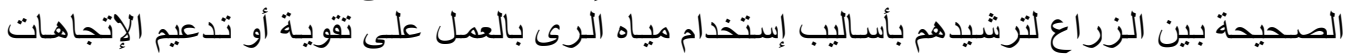

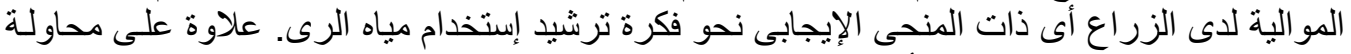

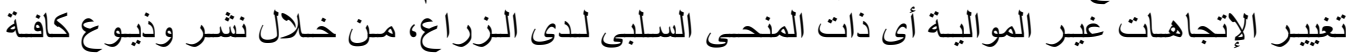

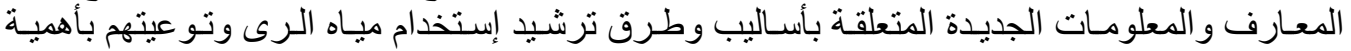

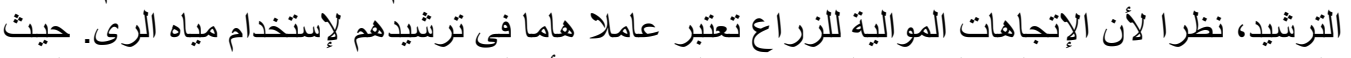

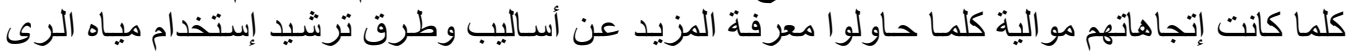

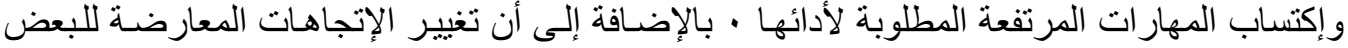

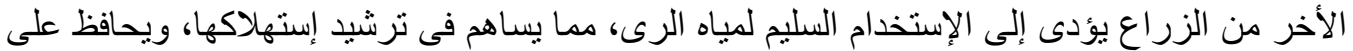

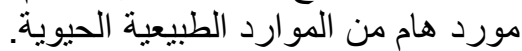

رابعا: المشكلات التي تواجه الزراع المبحوثين عند تلطيق أساليب ترشيد إستخدام مياه الرى:

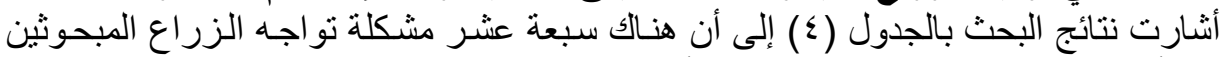

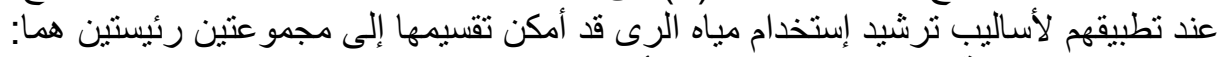

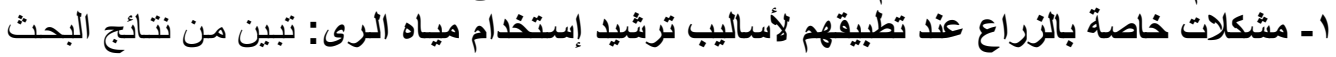

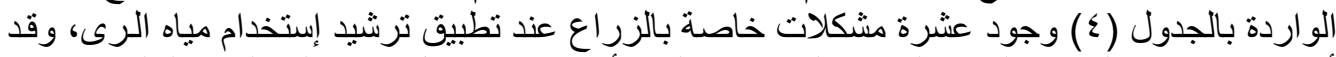

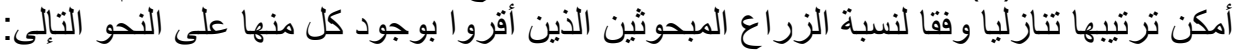

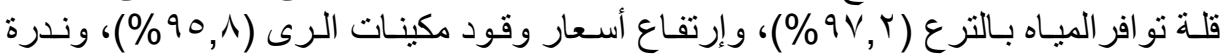

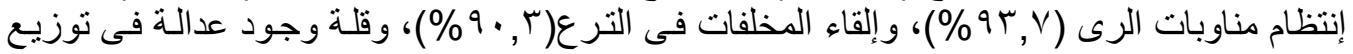

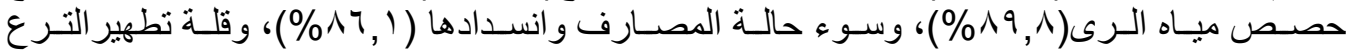

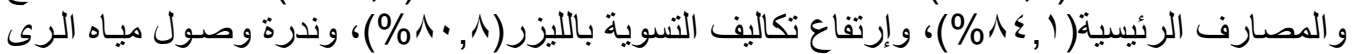

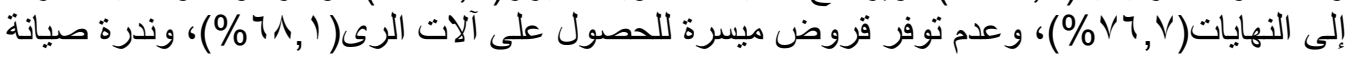

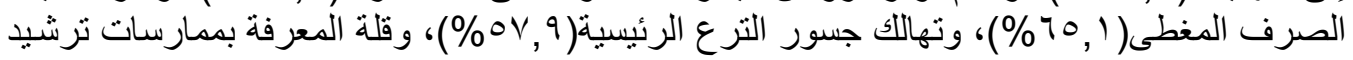

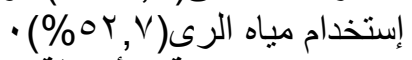

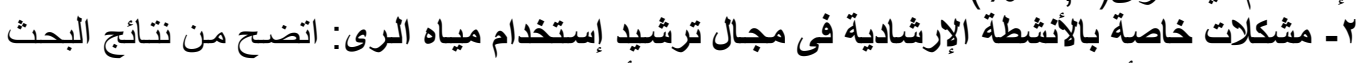

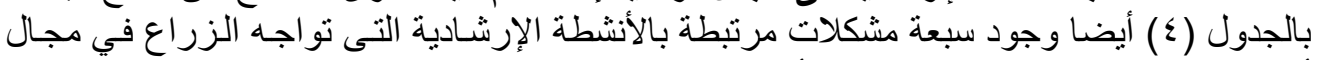

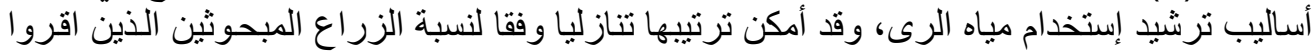

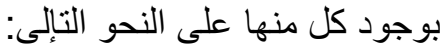

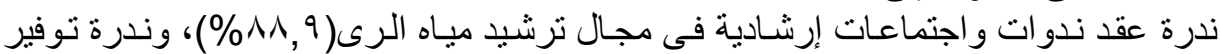

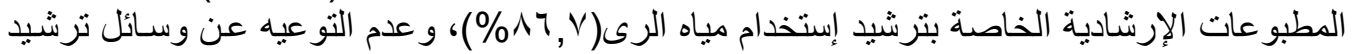

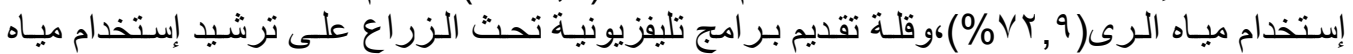

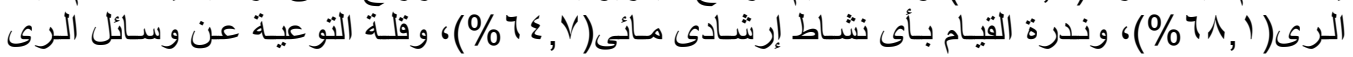

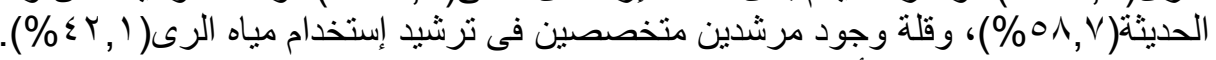

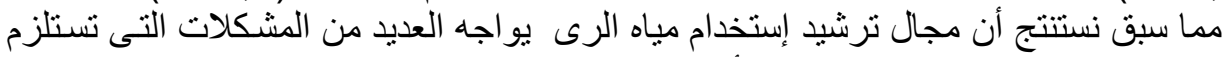

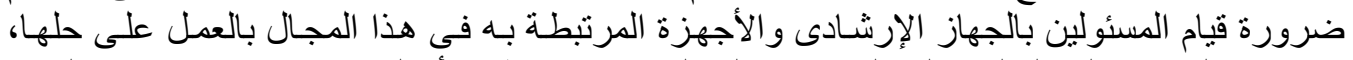

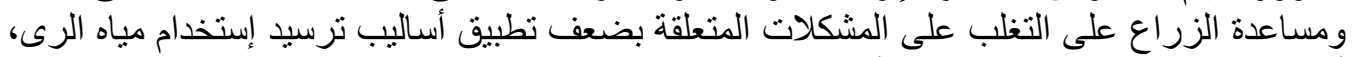

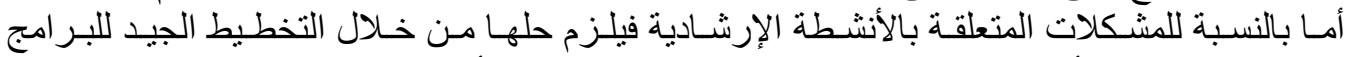

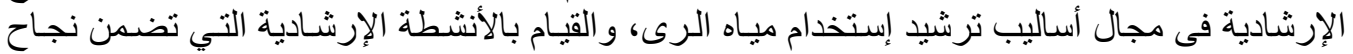

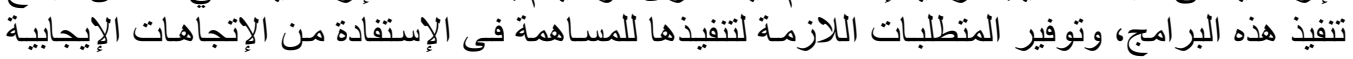

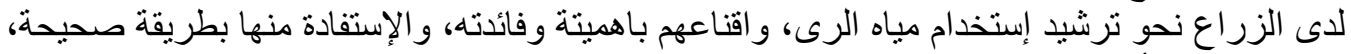

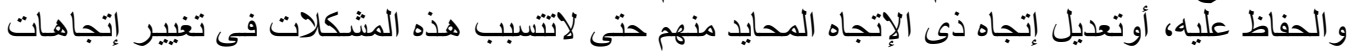
الزراع ذوى الإتجاه الإيجابى إلى سلبى. الإنى.

Fayoum J. Agric. Res. \& Dev., Vol. 27, No.2, July, 2014 
r

جدول ( ) التوزيع العدى والنسب المئوية والمتوسطات للزراع المبحوثين وفقاً لمستوى معرفتهم لأساليب ترشيد

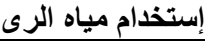

\begin{tabular}{|c|c|c|c|c|c|c|c|c|c|}
\hline \multirow{3}{*}{$\begin{array}{l}\overline{3} \\
\text { 㝵 } \\
3\end{array}$} & \multicolumn{8}{|c|}{ مستوى المعرفة } & \multirow[b]{3}{*}{ البنود } \\
\hline & \multicolumn{2}{|r|}{ لايعرف ل ل ل ل ل ل } & \multicolumn{2}{|c|}{ | منخفضة } & \multicolumn{2}{|c|}{ متوسطة } & \multicolumn{2}{|c|}{ 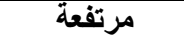 } & \\
\hline & $* \%$ & عدد & $* \%$ & عدد & $* \%$ & عدد & $* \%$ & عدد & \\
\hline$r, r)$ & 11,1 & $\varepsilon$. & $9, \mathrm{~V}$ & ro & $17, \mathrm{~V}$ & 7. & $\pi r, 0$ & TrO & 1-أضرار الإسر اف فى إستخدام مياه الرى \\
\hline$r, \cdot v$ & 11,1 & $\varepsilon$. & $r r, r$ & A. & $10, r$ & 00 & $01, \xi$ & 110 & r -أهم فو ائد ترشيد إستخدام مباه الرى \\
\hline $1, \wedge \Lambda$ & $r\urcorner, \varepsilon$ & 90 & 11,1 & $\varepsilon \cdot$ & 11,1 & $\varepsilon \cdot$ & $01, \varepsilon$ & 110 & ب-أهمبة تسوية الأرض بالليزر \\
\hline$r, T V$ & $1 \cdot, \cdot$ & r4 & $7, \mathrm{Y}$ & $r \varepsilon$ & $19, \varepsilon$ & $\mathrm{v}$. & $7 \pi, 9$ & rT. & عـ ـ أهمبة الزر اعة فى خطوط \\
\hline$r, \cdot 0$ & $17, \mathrm{~V}$ & 7. & 11,1 & $\varepsilon$. & Tr, & A. & $0 \cdot, \cdot \cdot$ & 11. & 0- فو ائد إستخدام طر يقة الرى فى خطوط \\
\hline $1, V \varepsilon$ & 4,7 & $11 \varepsilon$ & $1, \mathrm{~V}$ & 7 & $r V, \Lambda$ & $1 \ldots$ & $r \wedge, 9$ & $1 \leqslant$. & דـ-أهمية إثباع نظام الرى الليلى \\
\hline $1,0 \mathrm{r}$ & $r \cdot, \tau$ & 11. & $r \cdot, \Lambda$ & vo & $10, r$ & 00 & $r r, r$ & $\pi$ Tr. & Y-Yأهمبة تطهير المساقى الحقلية \\
\hline 1,81 & $r v, 0$ & 150 & 0,7 & r. & $r 4,1$ & $1 \%$. & $r \cdot \Lambda$ & vo & 1ـ- أهمية تطهير الترع عالفر عية \\
\hline 1,97 & $r \Lambda, T$ & 1.4 & 1,9 & $\mathrm{~V}$ & $1 \pi, 9$ & 0. & 00,7 & r.. & 9 ـ أهمبة تبطين المساقى الحقلية بالخرسانة \\
\hline 1,94 & $10, r$ & 00 & $r \cdot, T$ & $\mathrm{v \varepsilon}$ & $19, \mathrm{~V}$ & $\mathrm{VI}$ & $\varepsilon \varepsilon, \varepsilon$ & 17. & لـ ــ أهمية إنتعمال المصارف الدغظاه \\
\hline $1,7 \pi$ & $Y, \varepsilon$ & VV & $r \wedge, T$ & 1.4 & $17, \mathrm{~V}$ & 7. & $r \mu, r$ & IT. & إ 11 - أهمبة الدساقى الدنظورة \\
\hline $1, \sum \mathrm{V}$ & $r \varepsilon, V$ & Iro & $1 \cdot, 7$ & re & $r V, \Lambda$ & $1 \ldots$ & $r 7,9$ & $9 \mathrm{~V}$ & با با ـ فائدة الحرث تحت التزبة \\
\hline $1, \cdot 7$ & $r \varepsilon, \nu$ & Iro & $r v, r$ & $1 \pi \varepsilon$ & 10,7 & 07 & $1 r, 0$ & «0 & با إـ أضر ار إستخذام الرى بالغمر \\
\hline $1, \varepsilon \varepsilon$ & ro,o & 19. & $r 0,7$ & Irs & $\Lambda, r$ & $r$. & $r \cdot, 7$ & 11. & ع ـ ـ فائدة إنتخذام نظام الرى بالرفع \\
\hline$\cdot, \wedge \wedge$ & $\leqslant 7, \varepsilon$ & $17 \mathrm{~V}$ & $r \quad, 0$ & $11 \mathrm{~V}$ & 17,1 & 01 & $0, \cdots$ & 11 & 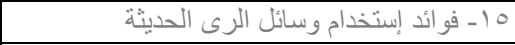 \\
\hline$\cdot, \wedge$. & $01, \varepsilon$ & 110 & $r v, \Lambda$ & $1 \ldots$ & $1 r, 0$ & ¿0 & $\Lambda, r$ & $r$. & 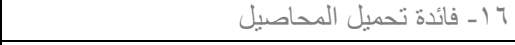 \\
\hline $1,0 \mathrm{r}$ & $r \cdot, \cdot$ & 1.1 & $r, 1$ & $\mathrm{~V} 7$ & 10,7 & 07 & $r r, r$ & IT. & V ا ـ ائدة إستخدام الرى بالرش و التنقيط \\
\hline 1,199 & $r \cdot, \cdot$ & $1 \cdot 1$ & Tr,T & 10 & IV,r & $T Y$ & $\varepsilon \cdot r$ & $1 \leq 0$ & 11 ــأهم الطرق لمعالجة مستوى الماء_الأرضى \\
\hline $1, \Sigma V$ & $r v, \Lambda$ & $1 \ldots$ & $r v, \Lambda$ & $1 \cdots$ & $1 \pi, 9$ & 0. & $r \cdot, 0$ & 11. & 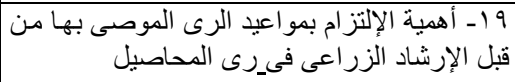 \\
\hline \multirow{2}{*}{\multicolumn{2}{|c|}{$r 1, r q$}} & & & & & & & & إجمالى المتوسط \\
\hline & & \multicolumn{7}{|c|}{$(\% 00) \quad 1,70$} & الـتوسط الحسابى الكلى \\
\hline
\end{tabular}

جدول ( r) التوزيع العددى والنسب المئوية والمتوسطات للزراع المبحوثين وفقاً لمستوى تطبيقهم

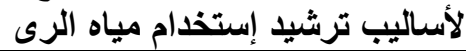

\begin{tabular}{|c|c|c|c|c|c|c|c|c|c|}
\hline \multirow{3}{*}{$\begin{array}{l}\overline{7} \\
\overline{3} \\
\overline{3}\end{array}$} & \multicolumn{8}{|c|}{ مستوى التطبيق } & \multirow{3}{*}{ البنـود } \\
\hline & \multicolumn{2}{|c|}{ لا يطبق } & \multicolumn{2}{|c|}{ نادرا } & \multicolumn{2}{|c|}{ أحيانا } & \multicolumn{2}{|c|}{ دائما } & \\
\hline & $* \%$ & عدد & $* \%$ & عدد & $* \%$ & عداد & $\star \%$ & عدد & \\
\hline$r, 00$ & - & - & $r, 0$ & 9 & $r 9, v$ & $1 \leqslant \mu$ & $O V, 1$ & $r \cdot \Lambda$ & 1-إجراء الحرث العميق قبل زراعةالمحصول \\
\hline $1, r)$ & $10, r$ & 00 & $\leqslant 9, \varepsilon$ & IVA & $r \pi, 9$ & ITr & $1,1$. & $\varepsilon$ & با-جراء التسوية بالليزر للأراضى مع إتجاه الرى \\
\hline$r, \cdot r$ & - & - & $1 \cdot, r$ & $\mu \nu$ & ov, 1 & TYY & $1 \varepsilon, 1$ & 01 & ب- ز- زراعة المحاصبل فى خطوط طويلة \\
\hline$r, \cdot r$ & - & - & $1 \cdot, \cdot$ & 47 & 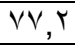 & TVA & $1 r, \Lambda$ & $\sum 7$ & ــ - إستخدام طريقة الرى فى خطوط \\
\hline$r, 7$. & - & - & $0, r$ & 19 & $r \wedge, q$ & $1 . \varepsilon$ & 70,1 & KTV & ه-إستخذام طريقة الرى بالرفع \\
\hline $1,9 \cdot$ &., 0 & $\bar{r}$ & $r q, \varepsilon$ & 90 & $00, r$ & 199 & $I V, \Lambda$ & $7 \varepsilon$ & †-رى المحاصيل و الأشجار ليلا حتى الصباح \\
\hline $5,4 q$ & 1,9 & $\mathrm{~V}$ & $\Lambda, 1$ & rq & $\varepsilon \wedge, q$ & $1 \times 4$ & $\varepsilon 1,1$ & $1 \leqslant \Lambda$ & ب-تيكير المساقى الحقلية \\
\hline 1,99 & $r \pi, r$ & $\Lambda \varepsilon$ & $\varepsilon 9, r$ & IVV & YY, Y & A. & $0, r$ & 19 & 1- م- تبطين قنوات الرى \\
\hline $1, Y, T$ & $\varepsilon \varepsilon, \varepsilon$ & 17. & $17, \mathrm{~V}$ & 7. & 11,1 & $\varepsilon$. & $r v, \Lambda$ & $1 \ldots$ & 9ـ قيام المز ارع بإجر اء الرى بطريقة الرش \\
\hline $1,0 \leqslant$ & $T V, \Lambda$ & $1 \ldots$ & $I V, 0$ & $7 \pi$ & $T V, \Lambda$ & $1 \ldots$ & $r 7,9$ & $9 \mathrm{~V}$ & • ا-قيام المز ارع بإجراء الرى بطريقة التنقيط \\
\hline$\cdot, \leqslant 1$ & $V T, 0$ & YTI & $17, \mathrm{~V}$ & 7. & $\Lambda, r$ & $r$. & $r, 0$ & 9 & | 1 - تطهير الترع الفرعية \\
\hline$r, T \leq$ & $r, \tau$ & $1 \pi$ & $\Lambda, r$ & $r$. & $\mathrm{v}, \Lambda$ & rA & $\Lambda \cdot, r$ & r19 & r إـ إتباع نظام المناوبات في الرى \\
\hline $1, \mathrm{VN}$ & 0,7 & r. & $r 1,1$ & $11 T$ & $\sum V, r$ & iv. & 17,1 & 01 & Tr ا - إستعمال المصارف المغطاه \\
\hline
\end{tabular}

Fayoum J. Agric. Res. \& Dev., Vol. 27, No.2, July, 2014 


\begin{tabular}{|c|c|c|c|c|c|c|c|c|c|}
\hline$r, 0$ & $r, \tau$ & 14 & $r \cdot, \Lambda$ & Vo & $\leqslant 1,9$ & 101 & $r r, v$ & $|r|$ & ع ا ــ إجراء العزيق قبل الرى \\
\hline$\cdot, 70$ & 71,1 & rY. & $19, \varepsilon$ & $V \cdot$ & 14,0 & $\leqslant 0$ & $v_{,} \cdot$ & ro & 10-تحميل محصول على محصول اخر \\
\hline \multicolumn{2}{|c|}{$r \varepsilon, \cdot r$} & & & & & & & & إجمالى المتوسط \\
\hline & & & $\left(\% 0^{\circ}\right.$ & & $1,7$. & & & & المتوسط الحسابى الكلى \\
\hline
\end{tabular}

جدول (r) التوزيع العددى والنسب المئوية للزراع المبحوثين وفقا لمستوى إتجاهاتهم نحو أساليب

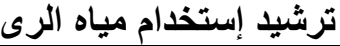

\begin{tabular}{|c|c|c|}
\hline$* \%$ & عدد & فئـات الإتجاه \\
\hline 10,1 & OV & إتجاه معارض اقل من ع درجة ) \\
\hline $07, \varepsilon$ & $r \cdot r$ & إتجاه محايد ( ع - - اقل من سب درجة) \\
\hline$r v, \wedge$ & $1 \cdots$ & إتجاه مو الى (اكثر من سب درجة ) \\
\hline $1 \ldots$ & ז. & المجموع \\
\hline
\end{tabular}

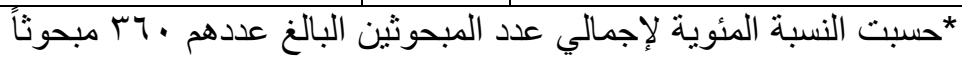


$r r$

جدول (؛ ) التوزيع العددى والنسب المئوية للزراع المبحوثين وفقا للمشكلات

التى تواجهم عند تطبيق ترشيد إستخدام مياه الرى الرئي

\begin{tabular}{|c|c|c|}
\hline \multicolumn{3}{|r|}{ المشكلات } \\
\hline \multicolumn{3}{|r|}{ أولا: مشكلات خاصة بالزراع عند تطبيق ترشيا إستخدام مياه الرى } \\
\hline $9 V, Y$ & ro. & ا _قلة تو افر المباه بالتر ع \\
\hline 90,1 & $r \leq 0$ & r- إرتفاع أسعار وقود مكينات الرى \\
\hline $9 \Gamma, \mathrm{V}$ & $r \leqslant r$ & " - ندرة إنتظام مناوبات الرى \\
\hline $9 \cdot, r$ & THO & عـ إلقاء المخلفات فى الترع \\
\hline$\wedge 9, \wedge$ & rrq & هـ قلة وجود عدالة فى توزيع حصص مياه الرى \\
\hline$\wedge 7,1$ & r. & 7-سوء حالة المصارف و انسدادها \\
\hline$\wedge \varepsilon, 1$ & $r \cdot \Lambda$ & V - قلة تطهير الترع و المصارف الرئيسية \\
\hline$\wedge \cdot, \wedge$ & r97 & 1- إرتفاع تكاليف التسوية بالليزر \\
\hline$\vee 7, V$ & rAl & 9 - ندرة وصول مياه الرى إلى النهايات \\
\hline 71,1 & $r \leqslant q$ & • ا ـعدم توفر قروض ميسرة للحصول على آلات الرى \\
\hline 70,1 & Tr人 & 1 ا ـ ندرة صيانة الصرف المغطى \\
\hline ov, 9 & rir & r ا - تهاللك ج \\
\hline or , $\mathrm{Y}$ & 194 & س ا ـ قلة المعرفة بممارسات ترشيد إستخدام مياه الرى \\
\hline \multicolumn{3}{|r|}{ ثانيا: مشكلات خاصة بالانشطة الإرشادية فى مجال ترشيد إستخدام مياه الرى } \\
\hline$\wedge \wedge, 9$ & Tr. & Iـ ندرة عقد ندوات واجتماعات إرشادية فى مجال ترشيد مياه الرى \\
\hline$\wedge \uparrow, \vee$ & Tr & r- ندرة توفير المطبو عات الإرشادية الخاصة بنرشيد إستخدام مياه الرى \\
\hline$V Y, q$ & rTV & r- عدم التو عيه عن وسائل ترشيد إستخدام مياه الرى \\
\hline $7 \wedge, 1$ & $r \leq q$ & ــ قلة تقديم بر امج تللفزيونية تحث الزراع على ترشيد إستخدام مياه الرى \\
\hline$T \varepsilon, V$ & tre & هـ ندرة القيام بأَى نـ \\
\hline $0 \wedge, \mathrm{V}$ & rio & 7ـ قلة التو عية عن وسائل الرى الحديثة \\
\hline$\varepsilon r, 1$ & $10 \leqslant$ & V- قلة وجود مرشدين متخصصين فى ترشيد إستخدام مياه الرى \\
\hline
\end{tabular}

*حسبت النسبة المئوية لإجمالي عدد المبحوثين البالغ عددهم • بـ مبحوثاً

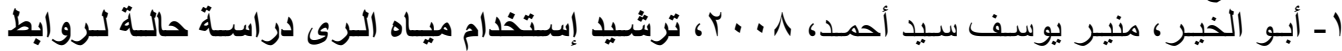

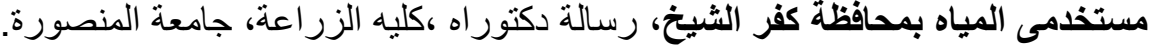

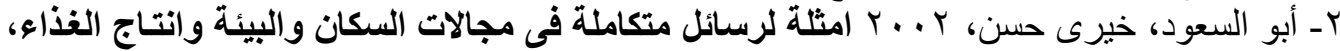

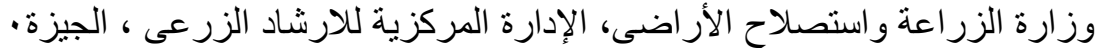

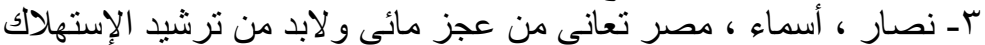

Available at:http://www,youm7,com/story/2014/10/7/,,1895840 visited in 12-7-2014

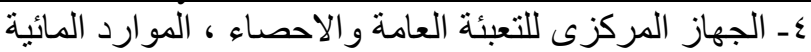

Availableat:http://www,resourcecrisis,com/index,php/water/679-135

visited

in: 161912014

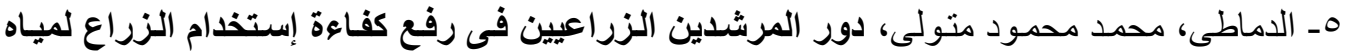

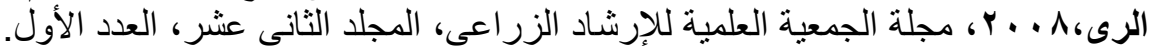

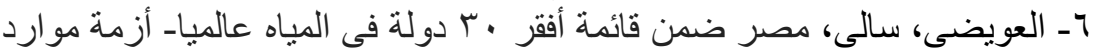

Available at: http://www,capmas,gov,eg/pages_ar,aspx?pageid=1160 visited in $: 1 / 6 / 2014$.

V- أمين، عاطف هلال، وأخرون، دراسة لبعض العوامل المؤثرة على تنفيذ الزراع لممارسـات ترشيد

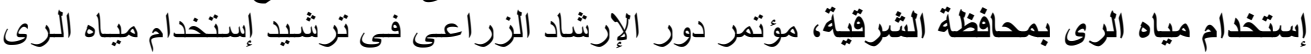

Fayoum J. Agric. Res. \& Dev., Vol. 27, No.2, July, 2014 
re

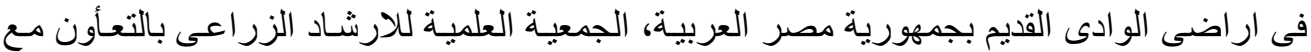

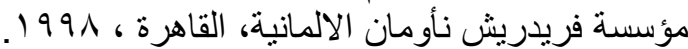

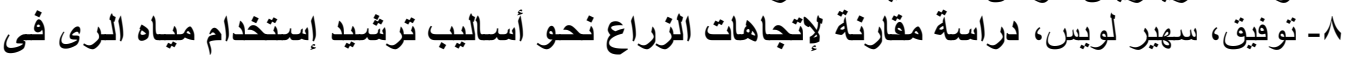

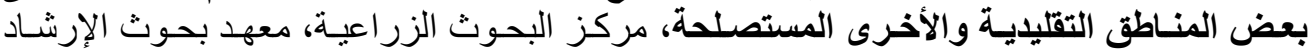

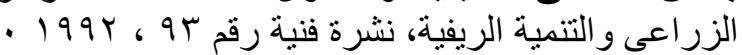

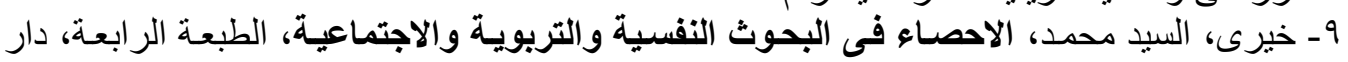

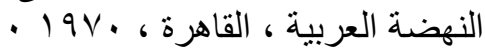

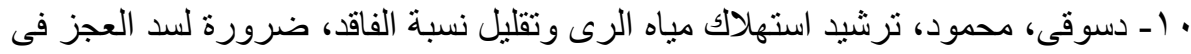
Available at http://digital,ahram,org,eg/articles,aspx?Serial=1458717\&eid=14555, visited in $: 1 / 8 / 2014$

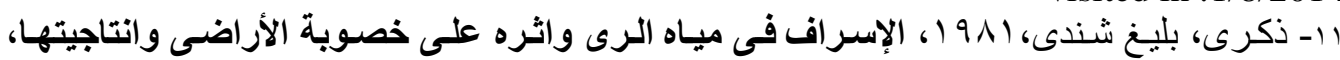

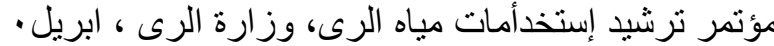

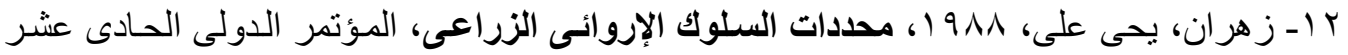

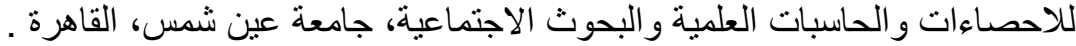

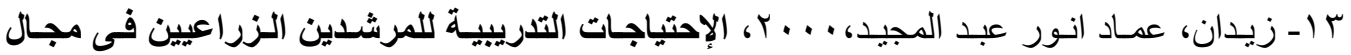

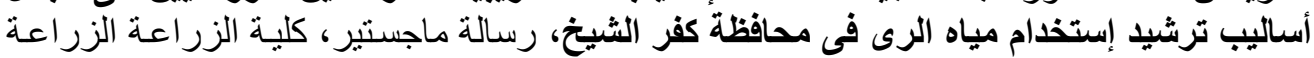

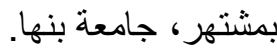

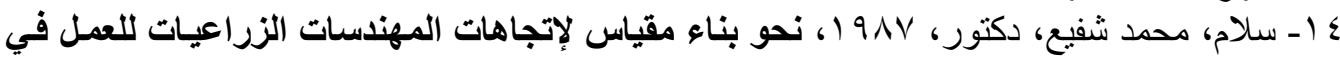

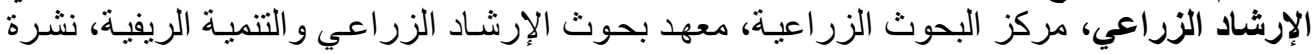

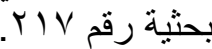

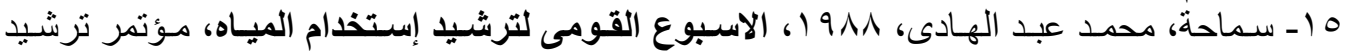

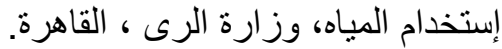

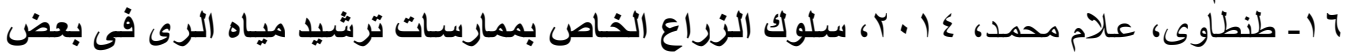

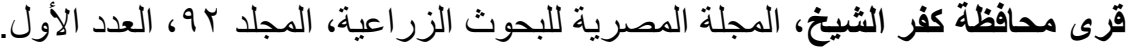

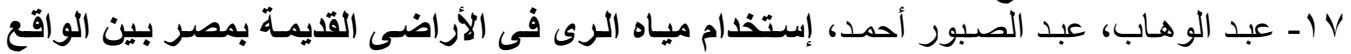

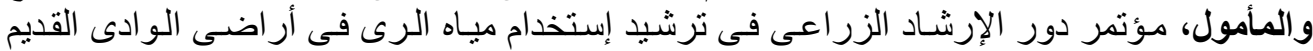

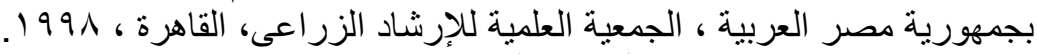

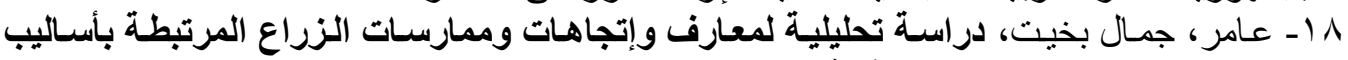

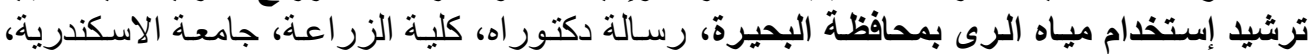

1919

9 ا ـ قاسم، حازم، المجلة الزر اعية، تطوير الرى الحقلى ضـرورة قوميـة، الأهر ام الرقمى، available .at:http://digital,ahram,org,eg/articles,aspx?Serial=374719\&eid=201visited in 1/9/2014

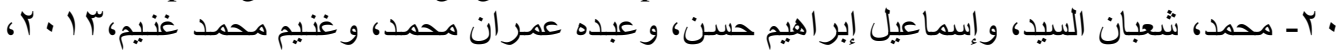

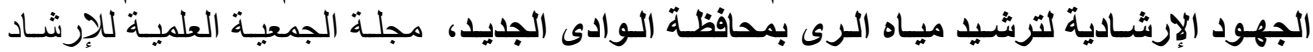

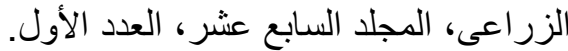

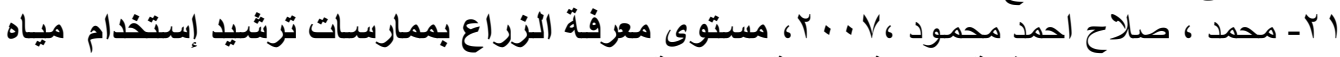

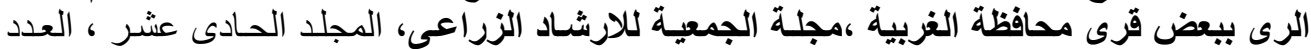

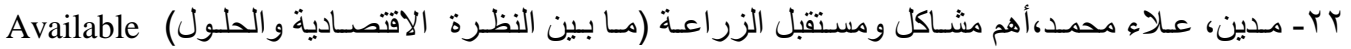
kesnanaonline,com/users/alaamadian/posts/542237 visited in 20/7/2014 at:http://

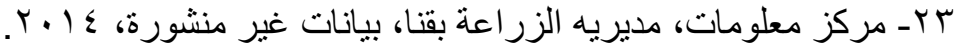

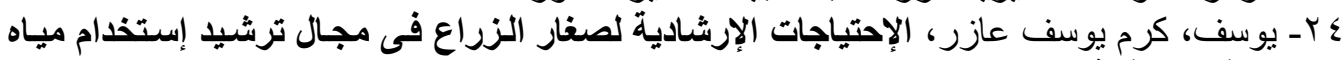

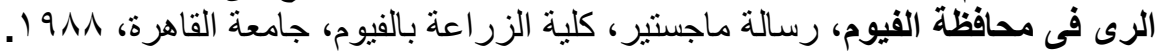

Fayoum J. Agric. Res. \& Dev., Vol. 27, No.2, July, 2014 
5-Kregice R,V, and Morgan, D,W, Educational and Psychological Measurement , college station, Durham, North Carolina, USA, 1970,

\begin{tabular}{|c|c|c|c|}
\hline \multirow{2}{*}{\multicolumn{4}{|c|}{ ملحق (1) عبارات القياس المستخذمة فى قياس إتجاه الزراع نحو أساليب ترشيد إستخدام مياه الرى }} \\
\hline غير & & & \\
\hline & & & 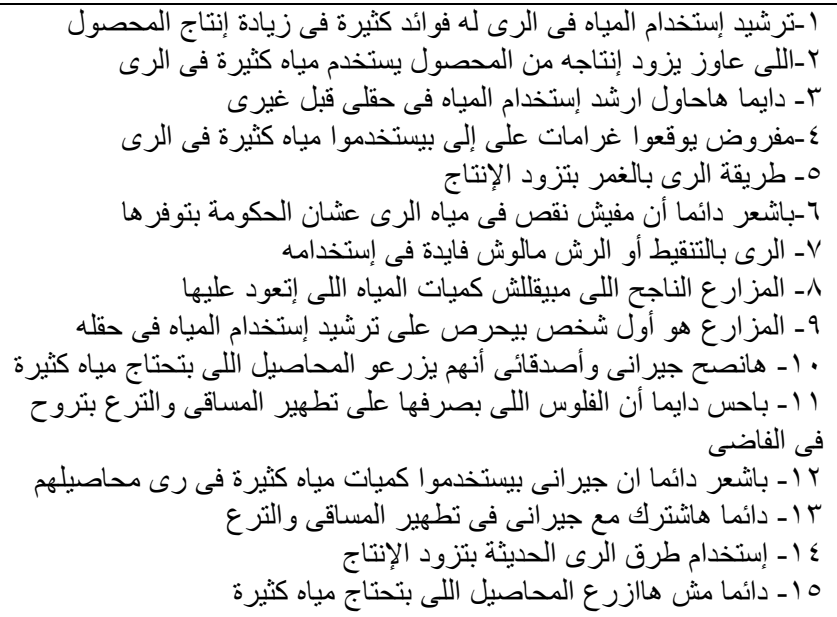 \\
\hline
\end{tabular}

Fayoum J. Agric. Res. \& Dev., Vol. 27, No.2, July, 2014 


\title{
THE BEHAVIORAL ASPECTS OF FARMERS RELATED TO RATIONALIZATION SYSTEMS OF IRRIGATION WATER USE IN QENA GOVERNORATE,
}

\author{
Dr. Abou El-Atta,T,M, \\ Dr/Saad,Amal Ismail Dr. Gomaa,Aml M \\ Agricultural Extension and Rural Development Researches Institute Agricultural \\ Researches Center,
}

\begin{abstract}
This study aimed at: determining the behavioral aspects of farmers related to rationalization systems of irrigation water use through determining the knowledge of the respondent farmers for the rationalization systems of irrigation water use, and the practices of the respondents for rationalization systems of irrigation water use in their fields,Also, the attitudes of the respondents, Towards rationalization systems of irrigation water use, determining the respondents' problems while applying rationalization practices of irrigation water use,
\end{abstract}

This research was conducted in Qena Governorate, three districts were chosen according to the planted area of field and horticultural crops, They are Qena,Deshna,Abo Tesht and,The sample was determined according to Kregciea and Morgan formula, The sample was chosen randomly in the season of 2013/2014 in these three villages It amounted 360 respondents representing $6,4 \%$ of the total amounted 5625 respondents, The sample was distributed in the research villages as follows:128 respondents in Dndara, 99 respondents in Abo Diab Shark, 133 respondents in Samhood,Personal interview with a questionnaire was used as a tool for collecting data ,Data were collected during March 2014 and they were presented using frequencies, percentages and averages,

The results of the study were as follows:

-The average of degrees means related to respondents' knowledge for rationalization systems of irrigation water use was 1,65 degree representing 55\%, This means that farmers' knowledge degrees were moderate,

- The average of degrees means of respondents' practices for rationalization systems of irrigation water use was 1,60 degree representing 53,3\%, This means that farmers' practices degrees were moderate,

-The percentage of farmers who were against rationalization systems of irrigation water use was $15,8 \%$ from the total sample, Also, the percentage of the sample which had neutral attitudes towards rationalization systems of irrigation water use was $56,4 \%$, While the percentage of the sample which had agreeable attitude was $27,8 \%$,

- The problems, which faced the respondents while applying the practices of rationalization systems of irrigation water use, were divided into: farmers' problems as follows; the shortage of canals water ,the high cost of using fuel in irrigation machines, throwing wastes in canals, irregular irrigation times, unfair of distribution irrigation water ,infecting canals and main drains, the cost of using laser, the absence of reaching water at the end, unavailability of loans to get irrigation machines, the absence of maintaining cover drains, the damage of main canals bridges, insufficiency of knowledge for rationalization practices of irrigation water use, Other problems concerning extension activities, were as follows; the absence of extension forums or meetings in the field of irrigation water rationalization, the absence of presenting $\mathrm{T}, \mathrm{V}$ programs concerning rationalizing the use of irrigation water, unavailability of extension pamphlets, unawareness of rationalization systems of irrigation water use, the absence of doing any water extension activity, unawareness of modern irrigation systems and the absence of specialized guides in rationalizing irrigation water use.

Fayoum J. Agric. Res. \& Dev., Vol. 27, No.2, July, 2014 